\title{
Mn-euvering manganese: the role of transporter gene family members in manganese uptake and mobilization in plants
}

\section{Amanda L. Socha * and Mary Lou Guerinot}

Department of Biological Sciences, Dartmouth College, Hanover, NH, USA

Edited by:

Felipe Klein Ricachenevsky,

Universidade Federal do Rio Grande

do Sul, Brazil

\section{Reviewed by:}

Jon Pittman, University of

Manchester, UK

Sebastien Thomine, Centre National de la Recherche Scientifique, France

Wolfgang Schmidt, Academia Sinica,

Taiwan

\section{*Correspondence:}

Amanda L. Socha, Department of

Biological Sciences, Dartmouth

College, 78 College Street, Hanover,

NH 03766, USA

e-mail: amanda.I.socha@

dartmouth.edu
Manganese (Mn), an essential trace element, is important for plant health. In plants, $\mathrm{Mn}$ serves as a cofactor in essential processes such as photosynthesis, lipid biosynthesis and oxidative stress. Mn deficient plants exhibit decreased growth and yield and are more susceptible to pathogens and damage at freezing temperatures. Mn deficiency is most prominent on alkaline soils with approximately one third of the world's soils being too alkaline for optimal crop production. Despite the importance of $\mathrm{Mn}$ in plant development, relatively little is known about how it traffics between plant tissues and into and out of organelles. Several gene transporter families have been implicated in Mn transport in plants. These transporter families include NRAMP (natural resistance associated macrophage protein), YSL (yellow stripe-like), ZIP (zinc regulated transporter/iron-regulated transporter [ZRT/IRT1]-related protein), CAX (cation exchanger), CCX (calcium cation exchangers), CDF/MTP (cation diffusion facilitator/metal tolerance protein), P-type ATPases and VIT (vacuolar iron transporter). A combination of techniques including mutant analysis and Synchrotron X-ray Fluorescence Spectroscopy can assist in identifying essential transporters of $\mathrm{Mn}$. Such knowledge would vastly improve our understanding of plant $\mathrm{Mn}$ homeostasis.

\section{Keywords: manganese, metal transport, Arabidopsis, rice, synchrotron x-ray fluorescence}

\section{INTRODUCTION}

With an increasing human population, there is a growing demand for improvements in crop production. Mineral nutrients such as iron $(\mathrm{Fe})$, copper $(\mathrm{Cu})$, and zinc $(\mathrm{Zn})$ are essential for both plants and animals, but maintaining optimal micronutrient levels presents challenges in both the plant and animal kingdoms. To combat human nutrient deficiency, efforts are being made to increase the bioavailability of nutrients in the edible portions of plants (Schroeder et al., 2013). Another concern is contamination of the soil with non-essential metal(oid)s such as arsenic $(\mathrm{As})$, lead $(\mathrm{Pb})$, cadmium $(\mathrm{Cd})$, and mercury $(\mathrm{Hg})$ (Salt et al., 1998). These elements are detrimental to both plants (through direct uptake from the soil) and humans (through consumption of contaminated plant products). One strategy for remediating soil contaminated with metals is using hyperaccumulator plants, which can tolerate and store remarkably high levels of metals in the aerial portion of the plant (Kramer, 2010). Mn is an example of an element that is both required in humans but can potentially be toxic. In excess, $\mathrm{Mn}$ can induce neurological symptoms that resemble Parkinson's disease (Martinez-Finley et al., 2013). Therefore, reducing human exposure to high levels of $\mathrm{Mn}$ is a major worldwide health concern. By better understanding the molecular mechanisms, specifically which transport proteins allow plants to take up and store metals, steps can be taken toward improved crop growth and the engineering of biofortified plants for improved human nutrition.
This review will focus on the micronutrient Mn. Despite its importance in cellular processes, such as photosynthesis and protecting cells against reactive oxygen species (ROS), little is known about transporters essential for Mn uptake and storage in the cell. We describe common and emerging techniques for assaying $\mathrm{Mn}$ localization and accumulation within the plant. In addition, we detail the protein families implicated in Mn transport. Particular emphasis will be placed on the model plant species Arabidopsis thaliana and Oryza sativa (rice), on which the majority of characterization work has been carried out. The transporter families will be organized based on their putative function of transporting $\mathrm{Mn}$ into or out of the cytoplasm. Table 1 summarizes the transporters discussed in this review. The subcellular localization (in A. thaliana and rice) and tissue localization (in A. thaliana) of the transporters is shown in Figures 1 and 2, respectively.

\section{SYMPTOMS OF Mn DEFICIENCY AND Mn TOXICITY}

$\mathrm{Mn}$ is a micronutrient element required for normal plant growth and development. It is essential for most photosynthetic organisms as a component of the oxygen-evolving complex in photosystem II (PSII), which catalyzes the water-splitting reaction to produce oxygen and provides electrons for the photosynthetic electron transport chain (Goussias et al., 2002; Nickelsen and Rengstl, 2013). Mn is also required for multiple steps in carbohydrate, lipid and lignin biosynthesis in plants (Marschner, 2012). Mn acts as a direct cofactor of a variety of enzymes 
Table 1 | Putative Mn transporters referenced in the text.

\begin{tabular}{|c|c|c|c|c|c|c|}
\hline Transporter & Tissue expression & $\begin{array}{l}\text { Subcellular } \\
\text { localization }\end{array}$ & $\begin{array}{l}\text { Transcript } \\
\text { response to Mn } \\
\text { deficiency }\end{array}$ & $\begin{array}{l}\text { Transcript } \\
\text { response to } \\
\text { Mn toxicity }\end{array}$ & $\begin{array}{l}\text { Other } \\
\text { proposed } \\
\text { substrates }\end{array}$ & References \\
\hline AtNRAMP1 & Root (all tissues) > shoot & PM & Up in root & -- & $\mathrm{Fe}, \mathrm{Cd}$ & $\begin{array}{l}\text { Curie et al., 2000; } \\
\text { Thomine et al., 2000; } \\
\text { Cailliatte et al., } 2010\end{array}$ \\
\hline AtNRAMP4 & $\begin{array}{l}\text { Shoot vasculature }>\text { root } \\
\text { vasculature, developing } \\
\text { seed }\end{array}$ & VM & None & -- & $\mathrm{Fe}, \mathrm{Zn}, \mathrm{Cd}$ & Thomine et al., 2000 \\
\hline OsNRAMP3 & $\begin{array}{l}\text { Nodes }>\text { root and leaf } \\
\text { vasculature, panicle, } \\
\text { husk, flower }\end{array}$ & PM & None & None (PTM) & & Yamaji et al., 2013 \\
\hline DMTI & Root, leaf, stems & $\begin{array}{l}\text { PM/peri- } \\
\text { bacteroid } \\
\text { membrane }\end{array}$ & -- & -- & $\mathrm{Fe}, \mathrm{Zn}, \mathrm{Cu}$ & Kaiser et al., 2003 \\
\hline LeNRAMP1 & Root & VM & -- & -- & & Bereczky et al., 2003 \\
\hline LeNRAMP3 & Root $>$ shoot & VM & -- & -- & & Bereczky et al., 2003 \\
\hline \multicolumn{7}{|l|}{ YSL FAMILY } \\
\hline AtYSL4 & $\begin{array}{l}\text { Shoot, silique, root, } \\
\text { flower, developing seed }\end{array}$ & VM/EM/CM & None & -- & $\mathrm{Ni}, \mathrm{Fe}^{* *}$ & $\begin{array}{l}\text { Conte et al., 2013; Divol } \\
\text { et al., } 2013\end{array}$ \\
\hline AtYSL6 & $\begin{array}{l}\text { Shoot, flower, silique, } \\
\text { developing seed }\end{array}$ & VM/EM/CM & None & -- & $\mathrm{Ni}, \mathrm{Fe}^{* *}$ & $\begin{array}{l}\text { Conte et al., 2013; Divol } \\
\text { et al., } 2013\end{array}$ \\
\hline OsYSL2 & $\begin{array}{l}\text { Leaf and leaf sheath } \\
\text { phloem, root phloem, } \\
\text { developing seed }\end{array}$ & PM & None & -- & $\mathrm{Fe}$ & Koike et al., 2004 \\
\hline \multicolumn{7}{|l|}{ ZIP FAMILY } \\
\hline AtIRT1 & Root epidermis, flower & PM & None & -- & $\begin{array}{l}\mathrm{Fe}, \mathrm{Zn}, \mathrm{Cu}, \mathrm{Cd} \text {, } \\
\text { Co }\end{array}$ & $\begin{array}{l}\text { Eide et al., 1996; } \\
\text { Korshunova et al., 1999; } \\
\text { Vert et al., } 2002\end{array}$ \\
\hline HvIRT1 & Root & PM, ER & None & - - & $\mathrm{Fe}, \mathrm{Zn}$ & Pedas et al., 2008 \\
\hline PsIRT1 & Root & PM & -- & -- & $\mathrm{Fe}, \mathrm{Zn}, \mathrm{Cd}$ & Cohen et al., 2004 \\
\hline LelRT1 & Root, flowers & -- & -- & -- & $\mathrm{Fe}, \mathrm{Zn}, \mathrm{Cd}$ & Eckhardt et al., 2001 \\
\hline LeIRT2 & Root & -- & -- & -- & $\mathrm{Fe}, \mathrm{Zn}, \mathrm{Cd}$ & Eckhardt et al., 2001 \\
\hline AtZIP1 & $\begin{array}{l}\text { Root vasculature }>\text { shoot } \\
\text { vasculature }\end{array}$ & VM & Up in shoot & -- & $\mathrm{Zn}$ & Milner et al., 2013 \\
\hline AtZIP2 & $\begin{array}{l}\text { Root vasculature }>\text { shoot } \\
\text { vasculature }\end{array}$ & PM & Down in shoot & -- & $\mathrm{Zn}$ & Milner et al., 2013 \\
\hline AtZIP5 & Root $>$ shoot & -- & -- & - - & & Milner et al., 2013 \\
\hline AtZIP6 & Root $>$ shoot & -- & -- & -- & & Milner et al., 2013 \\
\hline AtZIP7 & Shoot $>$ root & -- & -- & - - & $\mathrm{Zn}, \mathrm{Fe}$ & Milner et al., 2013 \\
\hline AtZIP9 & Root, shoot & -- & -- & - - & & Milner et al., 2013 \\
\hline MtZIP4 & Leaf, root* & $\begin{array}{l}\text { MM } \\
\text { (predicted) }\end{array}$ & Down in leaf & -- & & Lopez-Millan et al., 2004 \\
\hline
\end{tabular}


Table 1 | Continued

\begin{tabular}{|c|c|c|c|c|c|c|}
\hline Transporter & Tissue expression & $\begin{array}{l}\text { Subcellular } \\
\text { localization }\end{array}$ & $\begin{array}{l}\text { Transcript } \\
\text { response to Mn } \\
\text { deficiency }\end{array}$ & $\begin{array}{l}\text { Transcript } \\
\text { response to } \\
\text { Mn toxicity }\end{array}$ & $\begin{array}{l}\text { Other } \\
\text { proposed } \\
\text { substrates }\end{array}$ & References \\
\hline \multicolumn{7}{|c|}{ CAX FAMILY } \\
\hline AtCAX2 & $\begin{array}{l}\text { Root, shoot and flower } \\
\text { vasculature, fruit, stem }\end{array}$ & VM & -- & None & $\mathrm{Ca}, \mathrm{Cd}, \mathrm{Zn}$ & $\begin{array}{l}\text { Hirschi et al., 2000; } \\
\text { Schaaf et al., 2002; } \\
\text { Shigaki et al., 2003; } \\
\text { Pittman et al., 2004; } \\
\text { Edmond et al., } 2009\end{array}$ \\
\hline AtCAX4 & $\begin{array}{l}\text { Root, leaf, stem, flower, } \\
\text { silique }\end{array}$ & VM & -- & Up & $\mathrm{Cd}$ & Cheng et al., 2002 \\
\hline AtCAX5 & $\begin{array}{l}\text { Root, stem, fruit, flower, } \\
\text { leaf }\end{array}$ & VM & -- & Up & & Edmond et al., 2009 \\
\hline LeCAX2 & Leaf, fruit & -- & -- & -- & $\mathrm{Ca}$ & Edmond et al., 2009 \\
\hline $\mathrm{HvCAX2}$ & Root, shoot, seed & -- & -- & None & $\mathrm{Ca}$ & Edmond et al., 2009 \\
\hline \multicolumn{7}{|l|}{ CCX FAMILY } \\
\hline AtCCX3 & Flowers, stem, leaf, root & VM, EM & -- & $\begin{array}{l}\text { Up in root and } \\
\text { flowers }\end{array}$ & $\mathrm{Na}, \mathrm{K}$ & Morris et al., 2008 \\
\hline \multicolumn{7}{|c|}{ CDF/MTP FAMILY } \\
\hline AtMTP11 & $\begin{array}{l}\text { Leaf hydathodes, guard } \\
\text { cells, root tip }\end{array}$ & Golgi/PVC & -- & None & & $\begin{array}{l}\text { Delhaize et al., 2007; } \\
\text { Peiter et al., } 2007\end{array}$ \\
\hline OsMTP8.1 & Shoot & VM & None & Up in shoot & & Chen et al., 2013 \\
\hline ShMTP8 & -- & $\begin{array}{l}\text { Internal } \\
\text { organelle }\end{array}$ & -- & -- & -- & Delhaize et al., 2003 \\
\hline \multicolumn{7}{|c|}{ P-type ATPase FAMILY } \\
\hline AtECA1 & $\begin{array}{l}\text { Root vasculature, flower, } \\
\text { leaf vasculature, stem, } \\
\text { silique }\end{array}$ & ER & -- & -- & $\mathrm{Ca}, \mathrm{Zn}, \mathrm{Ni}$ & Wu et al., 2002 \\
\hline AtECA3 & $\begin{array}{l}\text { Root vasculature and tip, } \\
\text { Leaf vasculature, } \\
\text { hydathodes, guard cells, } \\
\text { flower, stem, silique }\end{array}$ & Golgi/EM & None & -- & $\mathrm{Ca}$ & Mills et al., 2008 \\
\hline LeLCA1 & -- & -- & -- & -- & $\mathrm{Ca}$ & Johnson et al., 2009 \\
\hline \multicolumn{7}{|c|}{ VIT/CCC1-LIKE FAMILY } \\
\hline AtVIT1 & $\begin{array}{l}\text { Developing seed, } \\
\text { vasculature }\end{array}$ & VM & -- & -- & $\mathrm{Fe}$ & Kim et al., 2006 \\
\hline OsVIT1 & $\begin{array}{l}\text { Leaf > root, stem, } \\
\text { panicle, embryo }\end{array}$ & VM & -- & -- & $\mathrm{Fe}, \mathrm{Zn}$ & Zhang et al., 2012 \\
\hline OsVIT2 & $\begin{array}{l}\text { Leaf > root, stem, } \\
\text { panicle, embryo }\end{array}$ & VM & -- & -- & $\mathrm{Fe}, \mathrm{Zn}$ & Zhang et al., 2012 \\
\hline
\end{tabular}

*Only during Zn deficiency. ${ }^{* *}$ Not observed by Conte et al. (2013). At, Arabidopsis thaliana; Hv, Hordeum vulgare; Ps, Pisum sativum; Le, Lycopersicon esculentum (Solanum lycopersicum); Mt, truncatula; Os, Oryza sativa; Zm, Zea mays; Bm, Beta vulgaris; PM, Plasma Membrane; ER, Endoplasmic Reticulum; VM, Vacuolar Membrane; MM, Mitochondrial Membrane; EM, Endomembrane Compartment; PVC, Pre-Vacuolar Compartment; GLC, Golgi-Like Compartment; PTM, Post-Translational Modification; - -, not tested. 


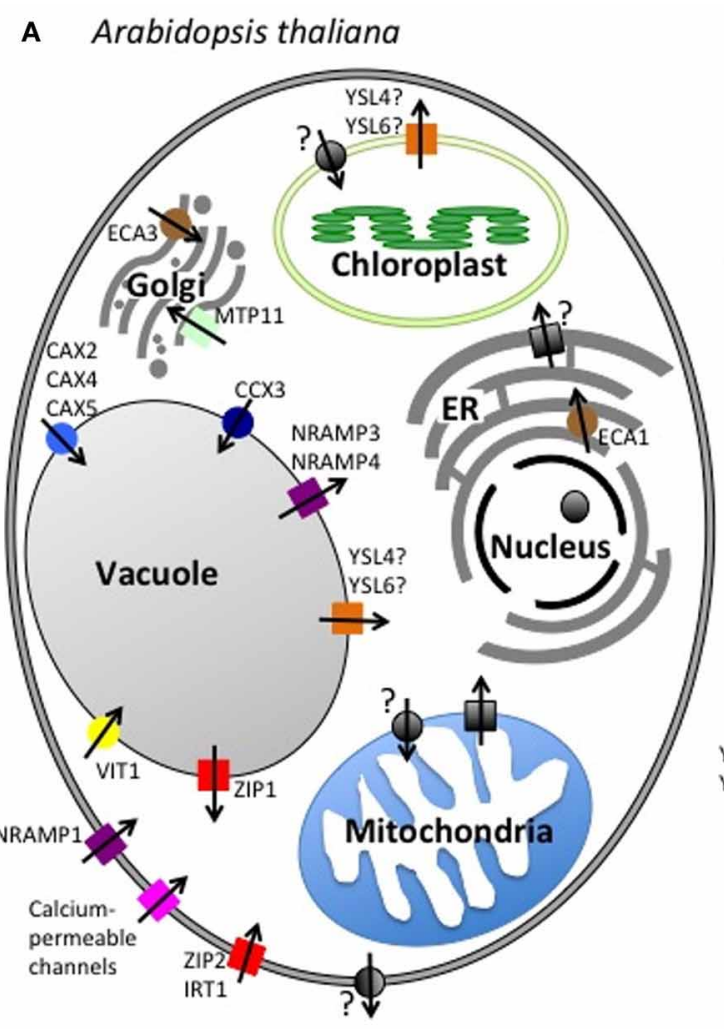

FIGURE 1 | Subcellular localization of putative Mn transporters. A diagram of a plant cell showing the $\mathrm{Mn}$ transport pathways in

(A) A. thaliana and (B) O. Sativa. Squares, import into the cytosol; Circles, export out of the cytosol; Gray, unknown; Red, ZIP family;

\section{B Oryza sativa}

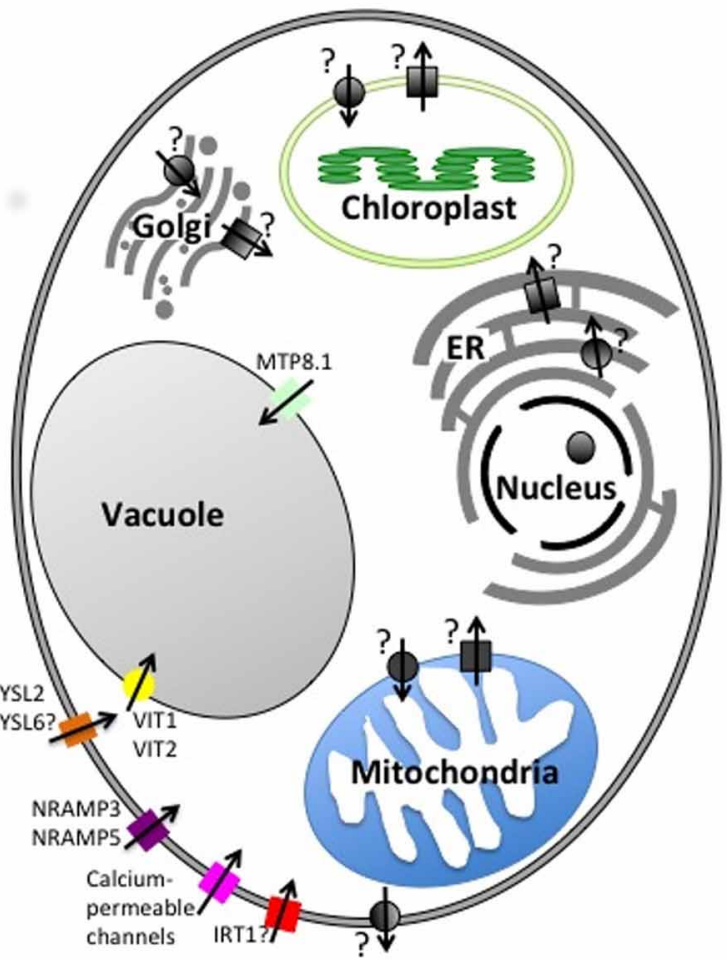

Magenta, Calcium-permeable channels; Orange, YSL family; Light blue, CAX family; Dark Blue, CCX family; Yellow, VIT family; Purple, NRAMP family; Brown, P2A-Type ATPase family; Green, CDF/MTP family.
( $\sim 35$ in plants), which include decarboxylases of the TCA cycle, RNA polymerases and numerous glycosyl transferases. In some enzymes, other metals can replace $\mathrm{Mn}$ as an enzymatic cofactor (Hebbern et al., 2009). Typically magnesium (Mg) replaces $\mathrm{Mn}$ because it is 50-100 times more abundant in the cell. Conversely, when $\mathrm{Mn}$ is in excess, it can replace $\mathrm{Mg}$, which can have detrimental effects on the cellular processes in which $\mathrm{Mg}$ is involved. There are some enzymes that specifically require $\mathrm{Mn}$ such as those involved in cellular redox reactions. $\mathrm{Mn}$ is an indispensable component of Mn superoxide dismutase (MnSOD), a principal antioxidant enzyme of the mitochondria. A recent study analyzing the effect of Mn deficiency on Chlamydomonas showed that MnSOD activity decreases before that of PSII (Allen et al., 2007). This finding suggests intracellular regulation of Mn to support PSII function in the chloroplast in preference to MnSOD function in the mitochondria.

Plant uptake of $\mathrm{Mn}$ is a function of the Mn oxidation state in the soil. While Mn can exist in a range of oxidation states $\left(\mathrm{Mn}^{1+}, \mathrm{Mn}^{2+}, \mathrm{Mn}^{3+}, \mathrm{Mn}^{4+}, \mathrm{Mn}^{6+}\right.$, and $\left.\mathrm{Mn}^{7+}\right)$, the most commonly found forms in biological systems are $\mathrm{Mn}^{2+}, \mathrm{Mn}^{3+}$ and $\mathrm{Mn}^{4+}$ with $\mathrm{Mn}^{4+}$ being the least stable (Marschner, 2012). The most soluble species in soil is the divalent cation, $\mathrm{Mn}^{2+}$, which is also the form of $\mathrm{Mn}$ that is most efficiently accumulated in plants (Marschner, 2012). Soil pH is a major determinant of $\mathrm{Mn}$ oxidation state in soil. At neutral or higher $\mathrm{pH}, \mathrm{Mn}^{3+}$ and $\mathrm{Mn}^{4+}$ predominate and insoluble Mn oxides will form (Rengel, 2000; Marschner, 2012). Mn solubility is also influenced by microorganisms, which can either reduce or oxidize Mn, thereby affecting its availability to the plant (Lovley et al., 2011; Geszvain et al., 2012).

Despite its necessity, $\mathrm{Mn}$ is required in relatively small amounts ( 20-40 milligrams per kilogram of dry weight in most crop species) (He et al., 2005; Jiang, 2006; Marschner, 2012). However, it is one of the most prevalent trace element deficiencies seen in cereals including wheat and barley (Jiang, 2006). Fertilizers containing Mn sulphate can be added to the soil, however this is costly and the added Mn can be oxidized making it unavailable for plant acquisition. A more cost-effective and eco-friendly alternative is to preferentially breed plants that are able to thrive in low $\mathrm{Mn}$ soil. There has been a significant effort to identify crop species that are considered Mn efficient and can tolerate growth on low $\mathrm{Mn}$, either by storing more Mn or by having an increased ability to absorb Mn from the soil (Jiang, 2006; Pedas et al., 2008). The genetic basis of Mn efficiency is not well understood.

Mn-deficient plants exhibit inhibited growth and decreased biomass (Marschner, 2012). Interveinal chlorosis due to decreases in net photosynthesis and chlorophyll content are common. This is most likely because the Mn-complex is needed to stabilize the PSII reaction center protein, D1 (Krieger et al., 1998; Allen et al., 2007; Yanykin et al., 2010). Mn-deficient plants are also 


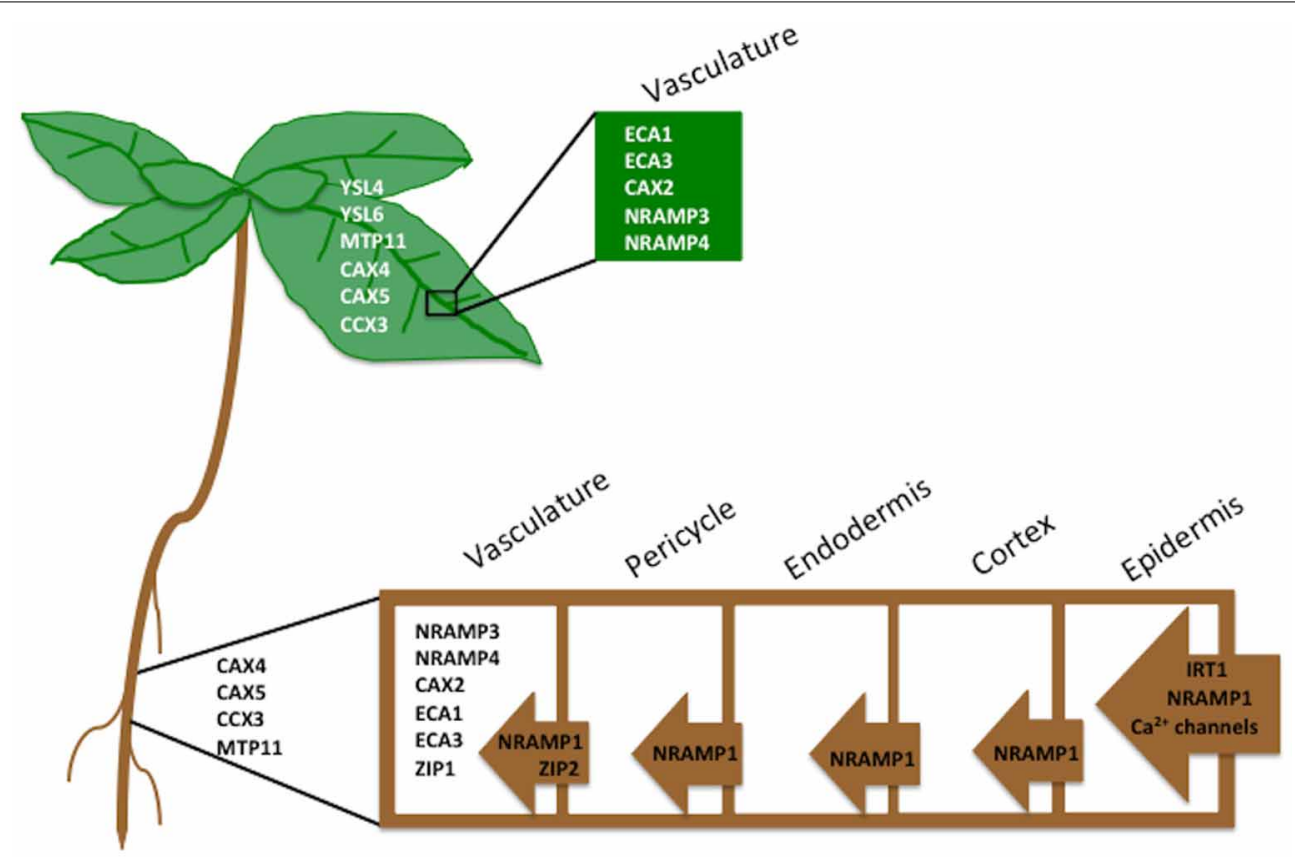

FIGURE 2 | Tissue localization of Mn transporters. The probable role of transporter family members in translocating $\mathrm{Mn}$ from the soil into the aerial portion of the plant in A. thaliana. The transporters listed to the left of the cells are not yet localized to a specific tissue.

characterized by tissue necrosis due to a decrease in MnSOD levels and an increase in oxygen free radicals (Allen et al., 2007; Marschner, 2012). Because Mn is a cofactor in the biosynthesis of cinnamic acid and its polymerization into lignin, decreased lignin concentration is especially prominent in the roots of $\mathrm{Mn}$ deficient plants (Marschner, 2012; Salvador et al., 2013). This is believed to be a contributing factor to an increased susceptibility to damage by freezing temperatures and root-infecting pathogens (Marschner, 2012). Mn deficiency can result from multiple factors including high concentrations of other minerals in the soil [i.e., Fe, $\mathrm{Mg}$, calcium (Ca), phosphorus (P)] that can interfere with $\mathrm{Mn}$ absorption as well as soil alkalinity $(\mathrm{pH}$ >7.5) (Lynch and St. Clair, 2004; Marschner, 2012). Highly calcareous soils and soils found in arid and semi-arid regions are described as too alkaline for vegetative growth (Lynch and St. Clair, 2004).

Mn toxicity can also be detrimental to plants. Toxicity can occur in poorly drained acidic soils $(\mathrm{pH}<5.5)$, where there is a predominance of $\mathrm{Mn}^{2+}$ (Lynch and St. Clair, 2004). Excess Mn can also prevent the uptake and translocation of other essential elements such as $\mathrm{Ca}, \mathrm{Mg}, \mathrm{Fe}$, and $\mathrm{P}$, presumably due to the similarity in ionic radius or binding strength for ligands (Marschner, 2012; Millaleo et al., 2013). In addition, toxicity can inhibit PSII and increase the accumulation of oxidized $\mathrm{Mn}$ and oxidized phenolic compounds in the leaf apoplast (Fecht-Christoffers et al., 2003; Marschner, 2012). As a result, common symptoms of Mn toxicity include interveinal chlorosis and tissue necrosis, which manifests as brown spots on mature leaves of plants, ultimately resulting in reduced plant biomass (Marschner, 2012). There are multiple mechanisms proposed to combat the deleterious effects of excess Mn. For example, plants can sequester Mn in the apoplast or vacuole (Horst and Maier, 1999; Hirschi et al., 2000; Schaaf et al., 2002). In fact, ectopic expression of vacuolar Mn transporters can increase the plant's tolerance to excess Mn (Delhaize et al., 2003). Free Mn ions can be chelated in metabolically inactive $\mathrm{Mn}^{2+}$-organic acid complexes (Horst and Maier, 1999; Pittman, 2005; Fernando et al., 2010). In addition, $\mathrm{Mn}^{2+}$ can be mobilized into the endoplasmic reticulum (ER), thereby reducing cytoplasmic Mn (Wu et al., 2002).

\section{TECHNIQUES FOR STUDYING METAL TRANSPORT AND ACCUMULATION IN PLANTS}

The range of metals transported by a particular transport protein can be determined by expressing the gene in a simpler model, usually yeast. Some of the yeast strains commonly used to test metal transport capabilities are $s m f 1$, fet3fet4, ctr1, and zrt1zrt2, which are unable to transport $\mathrm{Mn}, \mathrm{Fe}, \mathrm{Cu}$, and $\mathrm{Zn}$, respectively, across the plasma membrane (Dancis et al., 1994; Dix et al., 1994; Supek et al., 1996; Zhao and Eide, 1996a,b). Specific metal transport by a protein of interest is indicated by rescued growth of these yeast strains in a low $\mathrm{Mn}, \mathrm{Fe}, \mathrm{Cu}$ or $\mathrm{Zn}$ media or in the presence of a divalent metal chelator. For example, the $\operatorname{smf} 1$ mutant strain is unable to grow on media containing the divalent cation chelator EGTA. Another commonly used yeast strain to assay metal transport is pmr1. The $\mathrm{P}_{2}$-type Ca-ATPase, PMR1 (plasma membrane ATPase related 1) pumps both $\mathrm{Ca}^{2+}$ and $\mathrm{Mn}^{2+}$ in the Golgi for detoxification purposes or for use as a cofactor for Golgi-localized proteins (Rudolph et al., 1989; Durr et al., 1998). When PMR1 is defective, yeast are more sensitive to high concentrations of $\mathrm{Mn}^{2+}$ (Durr et al., 1998). Therefore, complementation of pmr1 
yeast with a Mn efflux transporter should restore growth when $\mathrm{Mn}$ in the media is high. Indirect studies using yeast, such as competition assays, are sometimes used to determine if a transporter has broad specificity (examples can be found in Grotz et al., 1998; Kaiser et al., 2003). However, further studies are necessary to confirm biological function.

Xenopus oocytes, immature eggs of an aquatic frog, are used to study the physiological function of a transporter. Electrophysiological measurements can be recorded in this system as well as uptake of radioactively labeled metals like ${ }^{54} \mathrm{Mn}$. This system also allows for the addition of any potential metal chelators necessary for Mn translocation across the membrane. While it is not clear whether Mn-specific metallochaperones exist in plants, Mn can complex with nicotianamine (NA), phytosiderophores (PS), phytate and organic acids (Koike et al., 2004; Haydon and Cobbett, 2007; Fernando et al., 2010).

Mn content in plant tissues or in yeast expressing a plant transporter is measured to demonstrate difference in Mn transport efficiency. To date, the most accurate and sensitive method to measure metal content in a sample is Inductively Coupled Plasma Mass Spectrometry (ICP-MS) (Baxter et al., 2008; Donner et al., 2012). However, because ICP-MS requires the total digestion of a sample, it does not collect spatial information about an element in vivo. For some metals, ion specific fluorophores exist, which, in conjunction with confocal microscopy, can image the subcellular localization of a metal (Burdette et al., 2001; Miller et al., 2006, 2008; Yoon et al., 2007), but there is currently no Mnspecific fluorescent probe. Therefore, other techniques are needed to spatially resolve Mn localization in a cell.

Quantitative in vivo cryo-scanning electron microscopy (SEM)/energy dispersive X-ray analysis (EDAX) has been used to provide detailed electron micrographs of tissue from hyperaccumulator plants along with energy dispersive X-ray spectra from regions of interest (Fernando et al., 2006b). The samples are prepared by rapidly freezing them in liquid nitrogen, which preserves the metal location during processing and microbeam exposure (Fernando et al., 2013). Further analysis using Particle-Induced $\mathrm{X}$-ray Emission induced by a focused ion beam ( $\mu$ PIXE) was used to confirm the cryo-SEM/EDAX results (Fernando et al., 2006a). Synchrotron X-Ray Fluorescence (SXRF) technology is a method used to localize metals in vivo at resolutions down to $250 \mathrm{~nm}$. For a review on how SXRF can be used to study gene function see Punshon et al. (2013). It is important to recognize that no one method stands alone in determining the role of a protein in $\mathrm{Mn}$ translocation and multiple methods must be used in parallel.

\section{MANGANESE LOCALIZATION IN PLANTA}

Intracellular $\mathrm{Mn}$ is found in multiple locations in the cell including the chloroplast, cell wall, mitochondria and Golgi apparatus (Pittman, 2005). Mn is also located in the vacuole, an organelle that is critical for cellular metal homeostasis, where it serves as an intracellular sink when metals are in excess and as a source when metals are limited (Pittman, 2005; Fernando et al., 2006a; Lanquar et al., 2010). Much of the Mn imaging in plant tissues has been performed on Mn hyperaccumulators, due to their unique metabolism and ease of imaging Mn-enriched tissues (Leitenmaier and Kupper, 2013). To date, there are around $22 \mathrm{Mn}$ hyperaccumulators identified around the world (Fernando et al.,

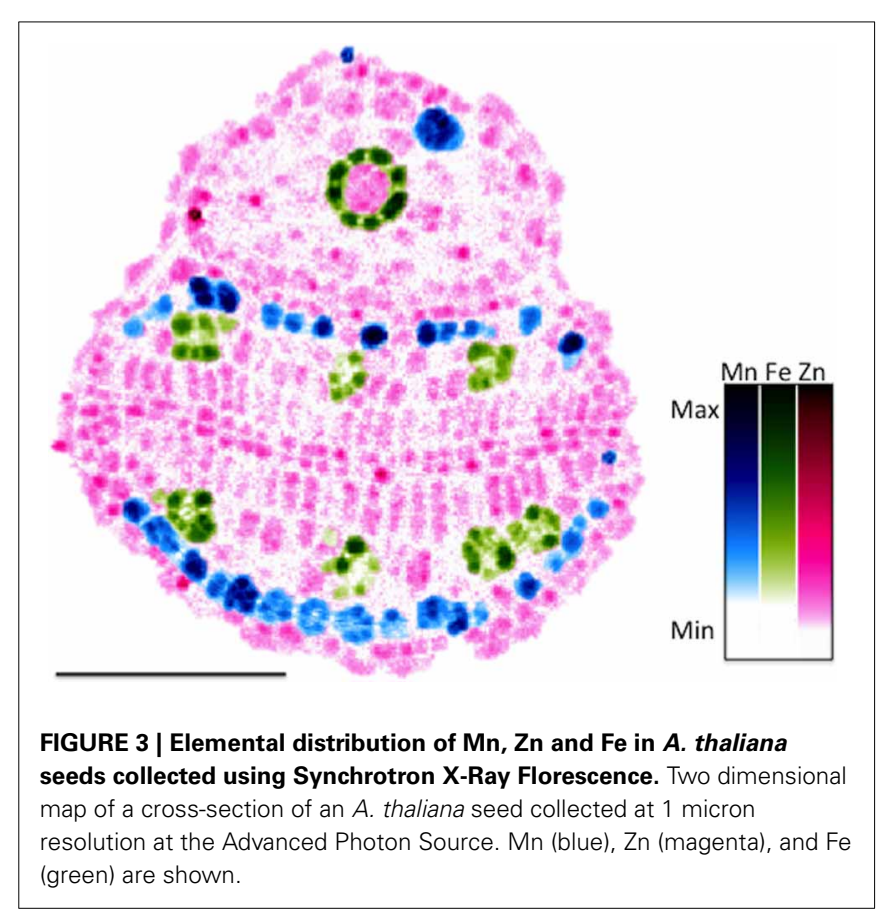

2013). The majority of hyperaccumulator plants' primary sequestration sites are in non-photosynthetic tissues such as trichomes (leaf hairs) and epidermal tissue. However, Mn hyperaccumulators can sequester excess $\mathrm{Mn}$ in photosynthetic tissues as well as non-photosynthetic tissues. In previous studies of five different Mn hyperaccumulators, excess foliar Mn was concentrated in the double layer of chloroplast containing palisade mesophyll cells in the leaf (Fernando et al., 2006a,b). In contrast, the Mn hyperaccumulator, Maytenus founieri, exhibited increased Mn accumulation in the non-photosynthetic leaf epidermal tissues, which is reminiscent of other metal hyperaccumulators such as the $\mathrm{Zn} / \mathrm{Cd}$ hyperaccumulator A. halleri (Fernando et al., 2008).

SXRF can be used to spatially localize and quantify $\mathrm{Mn}$ in A. thaliana seeds at a resolution high enough to resolve metals at a subcellular level (Donner et al., 2012). Recent studies using $\mu$ PIXE confirmed SXRF data that Mn is localized to spongy mesophyll on the abaxial side of the embryonic leaf (Kim et al., 2006; Schnell Ramos et al., 2013) (Figure 3). Donner et al. (2012) pointed out that, due to its requirement for photosynthesis, Mn needs to relocate to the palisade mesophyll cells during germination.

\section{MANGANESE TRANSPORTERS}

Studying the metal transport mechanisms of other species can greatly assist our understanding of how plants take up and distribute $\mathrm{Mn}$. While $\mathrm{Mn}$ transport is relatively understudied in plants, it is well understood in bacterial and yeast systems (Jakubovics and Jenkinson, 2001; Culotta et al., 2005; PappWallace and Maguire, 2006; Reddi et al., 2009). In the yeast, Saccharaomyces cerevisiae, $\mathrm{Mn}$ is transported into the cell through the high affinity $\mathrm{Mn}^{2+}$ transporter SMF1 of the NRAMP family (Supek et al., 1996) and the high affinity phosphate transporter, PHO84 (Jensen et al., 2003). PHO84-type phosphate transporters prefer neutral metal-phosphate complexes; therefore the substrate 
is presumed to be $\mathrm{MnHPO}_{4}$ (Jensen et al., 2003). The photosynthetic alga Chlamydomonas also encodes an NRAMP protein that is predicted to be involved in high affinity $\mathrm{Mn}^{2+}$ influx (Allen et al., 2007). Photosynthetic autotrophs such as cyanobacteria require Mn for PSII assembly and a gene product with sequence similarity to an ABC (ATP binding cassette)-type transporter is implicated in Mn uptake in this organism (Bartsevich and Pakrasi, 1995).

There are few Mn-only transporters identified in plants. One possible explanation is that Mn shares many of the same transporters as other divalent cations such as Fe. One study found that it might not be possible to uncouple Mn and Fe transport in one high affinity Fe transporter after systematically introducing point mutations into the metal binding domain of IRT1 (Rogers et al., 2000). In fact, the majority of transporters implicated in Mn translocation have broad specificity for several divalent cations including $\mathrm{Fe}, \mathrm{Zn}, \mathrm{Cu}, \mathrm{Cd}, \mathrm{Ca}$, Co (cobalt), Ni (nickel). The transporter families discussed below are organized based on transport of Mn into or out of the cytosol.

\section{TRANSPORT INTO THE CYTOSOL NRAMP family}

NRAMP1 was first characterized in mice as a gene involved in resistance to intracellular pathogens (Nevo and Nelson, 2006). Like many of the transporter families implicated in Mn transport, the NRAMPs transport a broad range of metals and can transport $\mathrm{Mn}^{2+}$ as well as $\mathrm{Fe}^{2+}, \mathrm{Zn}^{2+}, \mathrm{Cd}^{2+}, \mathrm{Cu}^{2+}, \mathrm{Ni}^{2+}, \mathrm{Co}^{2+}$, and $\mathrm{Al}^{3+}$ (Nevo and Nelson, 2006; Xia et al., 2010). The plant NRAMP proteins are predicted to be ion transporters based on sequence and predicted structural homology to the NRAMPs characterized in organisms such as humans and yeast. NRAMPs have between 10 and 12 transmembrane domains and a consensus transport sequence between transmembrane domains 8 and 9 that is shared with other ion channels and transporters (Cellier et al., 1995).

NRAMP proteins have been characterized in a number of plant species including Solanum lycopersicum, Glycine max, Malas baccata, Thlaspi japonicum and hyperaccumulators A. halleri and Thlaspi caerulescens (Bereczky et al., 2003; Kaiser et al., 2003; Mizuno et al., 2005; Xiao et al., 2008; Oomen et al., 2009). There are 6 and 7 NRAMP transporter proteins in A. thaliana and Oryza sativa, respectively. The first NRAMP genes cloned from plants were from rice in 1997 (Belouchi et al., 1997). However, not all are functionally characterized (Bennetzen, 2002; Nevo and Nelson, 2006).

Functional characterization of AtNRAMP1, AtNRAMP3, and AtNRAMP4 was first reported in 2000 (Thomine et al., 2000). AtNRAMP1 is believed to be a high affinity Mn transporter in the root due to the transcriptional upregulation of AtNRAMP1 in the root under Mn deficiency and its PM localization (Cailliatte et al., 2010). In addition, AtNRAMP1 expression increases in Fe deficiency and the protein complements yeast defective in Fe or Mn transport (Curie et al., 2000). Studies show that Arabidopsis Atnramp1 knockout lines are more susceptible to Mn deficiency, accumulate less $\mathrm{Mn}$ in the shoot when grown without $\mathrm{Mn}$ and have decreased $\mathrm{Mn}$ in the root when grown under Mn replete conditions (Cailliatte et al., 2010). Plants overexpressing AtNRAMP1 are more resistant to Mn deficiency. Elemental images of Mn in Atnramp1-1 mutant seeds shows wild type distribution of $\mathrm{Mn}$, therefore it is unlikely that these genes are necessary for Mn loading into the embryonic cotyledons (Donner et al., 2012).

AtNRAMP3 and AtNRAMP4 are also able to complement yeast deficient in either Mn or Fe uptake. Atnramp3-1 mutants show increased $\mathrm{Mn}$ in the roots of plants grown in Fe limited conditions while Mn accumulation decreased when AtNRAMP3 is expressed in the cell under control of the strong $35 \mathrm{~S}$ promoter (Thomine et al., 2003). This phenotype is possibly due to the vacuolar localization of this transporter. Expression data and transcriptional fusions to the promoters of AtNRAMP3 and AtNRAMP4 show that the transporters are expressed in the root stele and the vasculature of leaves and cotyledons and are highly upregulated during Fe deficiency (Thomine et al., 2000, 2003; Lanquar et al., 2005). AtNRAMP4 was identified as part of the vacuolar proteome in A. thaliana mesophyll cells (Carter et al., 2004). Translational fusions of both AtNRAMP3 and AtNRAMP4 proteins show that they are localized to the vacuolar membrane; therefore they are thought to be important for metal remobilization from the vacuole, in planta (Thomine et al., 2003).

AtNRAMP3 and AtNRAMP4 transporters are functionally redundant; only Atnramp3nramp4 double mutants exhibit a strong phenotype in response to metal deficiency. Both AtNRAMP3 and AtNRAMP4 are considered necessary for $\mathrm{Fe}$ remobilization during early germination due to their high expression levels at this growth stage (Lanquar et al., 2005). Lanquar et al. (2010) demonstrated that AtNRAMP3 and AtNRAMP4 are necessary for Mn export from the vacuole in the mesophyll cells of adult plant leaves. Double mutants have increased Mn accumulation in vacuoles. Under Mn deficiency, double mutants exhibit stunted growth and chlorosis when compared to wild type. Expression of either AtNRAMP3 or AtNRAMP4 in the double mutant can restore growth in Mn deficiency. Interestingly, it has been shown in other photosynthetic organisms that MnSOD activity decreases before there is a loss of function PSII in response to Mn deficiency (Allen et al., 2007). However, in Arabidopsis Atnramp3nramp4 double mutants, the level of active PSII decreases while there is no loss of MnSOD activity (Lanquar et al., 2010). These results suggest intra-organellar crosstalk between the chloroplast and vacuole that mediate proper $\mathrm{Mn}$ distribution in the cell.

To date, it is not known whether AtNRAMP2, AtNRAMP5 or AtNRAMP6 are important for Mn homeostasis.

Of the 7 NRAMPs in rice, only 4 have been functionally characterized. O. sativa plants utilize OsNRAMP3 to respond to environmental changes in Mn availability. OsNRAMP3 is constitutively expressed in the node of rice, which connects the vasculature of the root to aerial tissues of the plant (including the leaves, panicles and stems) (Yamaji et al., 2013). Under Mn deficiency, the PM localized OsNRAMP3 transports Mn from the transpiration stream in the xylem of enlarged vascular bundles to the younger tissues and panicles to meet minimal growth requirements. In contrast, when Mn is in excess, OsNRAMP3 is internalized in vesicles and rapidly degraded. Then, Mn is preferentially loaded into the older leaves, which are directly connected to the xylem-enlarged vascular bundles, thereby protecting developing 
tissue from Mn toxicity. This study demonstrates the importance of post-translational regulation in response to environmental nutrient availability.

OsNRAMP5, on the other hand, does not respond to varying levels of environmental $\mathrm{Mn}$, although gene expression increases slightly in the roots when plants are under Fe or $\mathrm{Zn}$ deficiency (Sasaki et al., 2012). Expression is seen in the mature zones of the root, more specifically at the PM of the exodermal and endodermal layers. Knockdown and RNAi lines accumulate less Mn in the roots and shoots and growth is stunted in response to Mn deficiency (Ishimaru et al., 2012; Sasaki et al., 2012). This phenotype is specific to Mn and not to other metal deficiencies tested, such as Fe-deficiency (Sasaki et al., 2012). Supplementing the plant with excess Mn does not rescue the growth defect. Therefore, it is likely that OsNRAMP5 is essential for Mn uptake from the soil in rice.

\section{YSL family}

The YSL transporters belong to a poorly characterized family of oligopeptide transporters (OPTs), which can transport amino acid-containing compounds and their derivatives (Yen et al., 2001). They are not found in all kingdoms, rather they are only found in plants, bacteria, fungi and archaea (Yen et al., 2001). The family is named after maize YS1 (ZmYS1), which accumulates in the root PM when Fe is scarce (Von Wiren et al., 1994; Roberts et al., 2004; Schaaf et al., 2004; Ueno et al., 2009). The characteristic interveinal chlorosis in the leaf of $y s 1$ knockdown mutants prompted the name "yellow stripe." Transport studies in both yeast and oocytes suggest that it can transport metals such as Mn, Zn, Cu, Ni, Cd as well as Fe (Schaaf et al., 2004). Therefore, it is reasonable to hypothesize that YSLs can transport Mn in other plant species.

YSL proteins mediate cellular uptake of metals complexed to non-proteinogenic amino acids: PS or its biosynthetic precursor NA (Yen et al., 2001). There is evidence that PS and NA are ligands for Mn (Schaaf et al., 2004; Haydon and Cobbett, 2007). Graminaceous plants (grasses) that include many crop species, use PS and NA for metal uptake and translocation, respectively (Palmer and Guerinot, 2009). PS is not produced by non-graminaceous plants (such as A. thaliana). Therefore, YSLs in non-grasses most likely use NA for intercellular and intracellular metal transport (Bashir et al., 2011).

There are eight predicted YSL genes in A. thaliana based on sequence similarity to YS1 (Curie et al., 2001). Knocking out a single AtYSL gene does not produce a strong visible phenotype (Didonato et al., 2004; Waters et al., 2006; Curie et al., 2009; Conte et al., 2013; Divol et al., 2013). However, it was discovered that if crosses are made between Atysl knockouts whose genes are in the same AtYSL subclass, a visible phenotype is observed. Examples include Atysl1ysl3, Atysl4ysl6, and Atysl5ysl7 (Curie et al., 2009; Conte et al., 2013; Divol et al., 2013). Proteomics studies of the Arabidopsis vacuole predicted AtYSL4 and AtYSL6 to be vacuolar-localized (Jaquinod et al., 2007). Evidence shows that they are either located at the vacuole/endocompartments (shown via translational fusions) or the chloroplast (shown via immunofluorescence) (Conte et al., 2013; Divol et al., 2013). Data suggests that these proteins may be effluxers of heavy metals from an internal cellular compartment. Conte et al. (2013) observed that in comparison to wild type and single mutants, the double mutant is more resistant to prolonged growth on excess $\mathrm{Mn}$. This phenotype was not reported by Divol et al. (2013). Thus far, the physiological role of AtYSL4 and AtYSL6 in Mn homeostasis remains to be clarified.

In rice, there are 18 putative YSL genes (Koike et al., 2004; Conte et al., 2013). OsYSL2 and OsYSL6 are implicated in Mn homeostasis. Electrophysiological and localization studies suggest the OsYSL2 is involved in lateral movement of $\mathrm{Mn}^{2+}-\mathrm{NA}$ complexes via the phloem and loading into developing seeds (Koike et al., 2004). OsYSL6 is required for Mn detoxification when soil Mn is in excess (Sasaki et al., 2011). OsYSL6 is expressed constitutively in all cells of the roots and the shoots, particularly in senescing leaves. GFP-fusions of the protein disrupt localization, but due to successful complementation of the $s m f 1$ yeast mutant, it is hypothesized to localize to the PM. When expressed in yeast, OsYSL6 translocates $\mathrm{Mn}^{2+}$-NA. In Osysl6 knockouts, plants exhibit symptoms of toxicity and excess Mn accumulates in the apoplast of the roots and shoots. When $\mathrm{Mn}^{2+}$ accumulates in the apoplast, it is oxidized into $\mathrm{Mn}^{3+}$, which in turn will oxidize proteins and lipids (Fecht-Christoffers et al., 2003). Therefore, it is probable that when plants are exposed to high levels of $\mathrm{Mn}$, OsYSL6 translocates Mn from the apoplast to the symplast where it is properly sequestered.

\section{ZIP family}

The ZIP gene family members are known to transport a broad range of metals including $\mathrm{Fe}^{2+}, \mathrm{Zn}^{2+}, \mathrm{Cd}^{2+}, \mathrm{Co}^{2+}$, and $\mathrm{Mn}^{2+}$ in both eukaryotes and prokaryotes (Korshunova et al., 1999; Guerinot, 2000). Structurally, they are composed of eight transmembrane domains with the $\mathrm{N}$ - and $\mathrm{C}$ - termini facing outside the PM. Their length and amino acid composition varies within the cytoplasmic variable region between transmembrane domains 3 and 4 . The variable region contains a conserved histidine motif that is believed to be important for metal binding and point mutations of inter-membrane domains can alter metal selectivity (Guerinot, 2000; Rogers et al., 2000).

The ZIP family of metal transporters is named for its founding members in both $S$. cerevisae and A. thaliana, respectively (Grotz et al., 1998). Of the 16 ZIP transporters in Arabidopsis, few have been functionally characterized (Maser et al., 2001; Rampey et al., 2013). IRT1 (Iron Regulated Transporter 1) is a high affinity Fe transporter that also has low affinity for other metals including Mn (Eide et al., 1996; Korshunova et al., 1999; Vert et al., 2002; Yang et al., 2008). It is upregulated in Fe deficient roots. In addition, exogenous $\mathrm{Mn}$ cannot rescue the chlorotic phenotype of irt1 mutants, which only grow in the presence of excess Fe (Vert et al., 2002). However, irt1 mutant plants accumulate less $\mathrm{Mn}$ in their tissues during Fe deficiency, suggesting that IRT1 is a major pathway for $\mathrm{Mn}^{2+}$ uptake when Fe is scarce (Connolly et al., 2002). Because Mn uptake is still required for the plant during Fe replete conditions, there is likely another PM membrane localized transporter on the root epidermis that can transport $\mathrm{Mn}$. Interestingly, under $\mathrm{Mn}^{2+}$ deficiency, IRT1 transcript levels decrease and Fe transport increases as evidenced by high Fe concentrations in the plant (Yang et al., 2008). 
A more recent study found that in addition to AtIRT1, six A. thaliana ZIPs could restore growth to the Mn uptake defective smf1 mutant: AtZIP1, AtZIP2, AtZIP5, AtZIP6, AtZIP7, and AtZIP9 (Milner et al., 2013). AtZIP3, AtZIP4, AtZIP10, AtZIP11, AtZIP12 did not. AtZIP8 is a pseudogene in Arabidopsis and this did not complement any of the yeast strains used in the study. Under normal conditions, AtZIP1, AtZIP2, and AtZIP6 are more highly expressed in the root while AtZIP7 transcript is more highly concentrated in the shoot. AtZIP5 and AtZIP9 transcripts are not very abundant and can be found in the root and shoot. The physiological roles of AtZIP6, AtZIP7, and AtZIP9 in Mn homeostasis in planta remain to be explored.

AtZIP1 is most highly expressed in the root stele and is localized to the vacuole (Milner et al., 2013). AtZIP1 is believed to remobilize $\mathrm{Mn}$ from vacuoles into the cytoplasm to allow for their translocation to the shoot. This function is supported by the phenotype of Atzip1 T-DNA insertion lines, which are more sensitive to low Mn and accumulate more Mn in the root. AtZIP2 is proposed to supply Mn to the aerial tissues in the plant via the root vasculature and not through direct uptake from the soil based on it localization to the PM in the root stele. In addition, mutant plants lacking functional AtZIP2 are more tolerant to Mn toxicity and less tolerant to Mn-deficiency, suggesting their importance in $\mathrm{Mn}$ translocation to the shoot for sequestration of excess $\mathrm{Mn}$ or normal plant health. However, it is unlikely that AtZIP2 is the primary transporter of $\mathrm{Mn}$ in the root because gene expression decreases during Mn deficiency.

To date, the literature does not detail any OsZIPs that are able to transport Mn. However, OsZIP5 transcript was slightly induced in the root upon Mn deficiency (Lee et al., 2010). Yet, it was not able to rescue $s m f 1$ mutants and is therefore unlikely to be a direct transporter of Mn. ZIPs are described in other plant species, aside from Arabidopsis, that transport Mn. These species include Solanum lycopersicum, Pisum sativa, Hordeum vulgare, and Medicago truncatula (Eckhardt et al., 2001; Bereczky et al., 2003; Cohen et al., 2004; Lopez-Millan et al., 2004; Pedas et al., 2008). Tomato LeIRT1 and LeIRT2 along with PsIRT1, HvIRT1, MtZIP4, and MtZIP7 can restore growth to smf1 mutants in Mn limited media. In barley, Mn efficiency correlates with increased expression of HvIRT1, an OsIRT1 ortholog, in roots (Pedas et al., 2008).

\section{Calcium-permeable channels}

Calcium-permeable channels located in the PM of the root cells are a $\mathrm{Ca}^{2+}$ influx pathway that may be permeable to $\mathrm{Mn}^{2+}$ (White et al., 2002). Initial studies of these channels used biochemical and electrophysiological experiments to characterize their role in catalyzing cation influx because the genes encoding these channels had not been identified. A subset of cation channels that may be permeable to $\mathrm{Mn}^{2+}$ (as well as a broad range of other cations) are found in the apical PM of Arabidopsis root hairs (Very and Davies, 2000), protoplasts from the endodermis, cortex and root elongation zone and the epidermis of a developing root tip (Kiegle et al., 2000). They are also identified in the stele of maize roots (White et al., 2002). In addition, LCT1, a gene in wheat roots that is potentially a $\mathrm{Ca}^{2+}$-permeable channel, was cloned and heterologously expressed in a yeast mutant where the transport of $\mathrm{Ca}^{2+}$ is blocked by the addition of $\mathrm{Mn}^{2+}$ to the media (Clemens et al., 1998). There is further evidence based on competition assays that $\mathrm{Ca}^{2+}$-permeable channels transport $\mathrm{Mn}^{2+}$ in A. thaliana root hair tips (Wymer et al., 1997) and maize roots (Marshall et al., 1994).

\section{EXPORT FROM THE CYTOSOL CAX family}

The CAX proteins are one of five transporter families that constitute the $\mathrm{Ca}^{2+} /$ cation antiporters (CaCA) superfamily (Shigaki and Hirschi, 2006; Emery et al., 2012). Although the CAX family members were originally identified as $\mathrm{Ca}^{2+}$ transporters, further study revealed their ability to transport a wide array of ions, hence their name modification from "calcium exchanger" to "cation exchanger." Typically, the CAXs contain 11 transmembrane domains and are found in plants, fungi and bacteria and in lower vertebrates. They facilitate the redistribution of cations across a membrane using electrochemical energy generated by a proton pump in order to maintain optimal ionic concentrations in the cell.

There are six CAX proteins in A. thaliana, which are split into two distinct phylogenetic groups: AtCAX1, AtCAX3, and AtCAX4 are part of the Type IA subgroup and AtCAX2, AtCAX5, and AtCAX6 are part of the Type 1B subgroup (Shigaki et al., 2006). The biological significance of the subgroups is unclear. In plants, the CAXs mediate efflux of ions into the vacuole. AtCAX2 contains a three-amino acid $\mathrm{Mn}^{2+}$ binding domain (Cys-Ala-Phe) between transmembrane domain 4 and transmembrane domain 5 (Shigaki et al., 2003). Expression of AtCAX2 in yeast can confer tolerance to $\mathrm{Mn}^{2+}$ toxicity (Schaaf et al., 2002; Shigaki et al., 2003). Furthermore, ectopic expression of AtCAX2 in tobacco (Nicotiana tabacum) can mediate vacuolar sequestration of $\mathrm{Mn}$ and confer resistance to high Mn stress (Hirschi et al., 2000), indicating a $\mathrm{Mn}$ transport function. In A. thaliana, AtCAX2 is expressed at low levels in all tissues and does not respond to changes in Mn availability (Hirschi et al., 2000). However, Arabidopsis Atcax 2 mutants accumulate significantly less $\mathrm{Mn}$ in the vacuole compared to wild type (Pittman et al., 2004). The Atcax 2 knockout mutants display no obvious phenotype, even under Mn stress, and some Mn does continue to accumulate in the vacuole, suggesting that there are other vacuolar transporters that can compensate for the absence of AtCAX2 (Pittman et al., 2004). Candidates include AtCAX4 and AtCAX5 along with the AtCCX3 and AtVIT1 transporters, which will be discussed below.

AtCAX4 and AtCAX5 are likely involved in $\mathrm{Mn}^{2+} / \mathrm{H}^{+}$antiport activity. Like AtCAX2, AtCAX4, and AtCAX5 are located at the vacuolar membrane and are constitutively expressed at low levels in all tissues (Cheng et al., 2002; Edmond et al., 2009). AtCAX5 is most highly expressed in the stem and root and AtCAX4 is more highly expressed in the roots (determined via qRT-PCR) and plays a role in root growth under ion stress, such as $\mathrm{Mn}^{2+}$ toxicity (Edmond et al., 2009; Mei et al., 2009). Interestingly, AtCAX4 and AtCAX5 RNA levels increase when plants are exposed to high $\mathrm{Mn}^{2+}$ (Cheng et al., 2002; Edmond et al., 2009; Mei et al., 2009). AtCAX4 increases Mn stress tolerance when expressed in tobacco and AtCAX5 can rescue Mn-sensitive yeast, indicating 
their ability to transport Mn (Korenkov et al., 2007; Edmond et al., 2009).

Thus far, single Atcax mutants do not exhibit strong phenotypes, even when exposed to Mn stress. This is possibly due to functional redundancy of the AtCAX proteins. A subset of double mutants in Arabidopsis are reported in the literature: Atcax1cax3, Atcax2cax3, and Atcax1cax2 (Connorton et al., 2012; Punshon et al., 2012). AtCAX1 appears to be important for determining the phenotype of a double mutant plant. A study by Connorton et al. (2012), found that Atcax2 and Atcax2cax3 mutants are both more sensitive to high Mn than wild type. However, the Atcax1cax2 double mutant does not display any signs of Mn toxicity, suggesting that by deleting Atcaxl from the Atcax 2 mutants, $\mathrm{Mn}$ is once again able to accumulate in the vacuole. The phenotype of the Atcax 1 cax2 mutant is consistent with the phenotype of the plants lacking a functional AtCAX1 gene, which are also more tolerant to $\mathrm{Mn}$ toxicity. Therefore, it will be important to understand the apparent cross-talk that occurs between the AtCAX proteins, which confers their Mn transport capabilities.

There are five CAX proteins in the rice genome, all of which have been cloned and their transport specificities assessed in yeast (Kamiya et al., 2005). OsCAX1a and OsCAX3 confer Mn tolerance in yeast, therefore they are potentially $\mathrm{Mn}^{2+} / \mathrm{H}^{+}$exchangers in planta (Kamiya and Maeshima, 2004; Kamiya et al., 2005). It is important to note that CAX proteins can also transport $\mathrm{Mn}$ in other plant species. Examples include HvCAX2 in barley and LeCAX2 in tomato (Edmond et al., 2009). Future work is needed to confirm that they are also localized to the vacuole in planta, where they mediate Mn tolerance.

\section{CCX family}

CCXs are one of five families of transporters, (along with the CAXs) which make up the CaCA superfamily (Shigaki et al., 2006; Emery et al., 2012). There are five CCX proteins (CCX1-5), which were previously identified as CAX7-11. They were reclassified due to their higher sequence homology to the mammalian $\mathrm{PM} \mathrm{K}^{+}$-dependent $\mathrm{Na}^{+} / \mathrm{Ca}^{2+}$ exchangers (NCXs). Expression of AtCCX3 in yeast rescues mutants defective in either PM or vacuolar import of $\mathrm{Mn}^{2+}$ (Morris et al., 2008). However, GFP and HA tagged versions of the protein support localization to intracellular compartments. Wild type yeast expressing AtCCX3 had nearly double the Mn concentration when compared to yeast expressing the control vector. Also, when ectopically expressed in tobacco, plant $\mathrm{Mn}^{2+}$ concentration significantly increased as leaves matured, which led to tissue necrosis. This phenotype is likely due to the defects in ion homeostasis in the plant resulting in increased ROS as evidenced by higher oxidation of proteins compared to controls. In plants, treatment with $\mathrm{Mn}$ induces $A t C C X 3$ expression in roots and flowers (Morris et al., 2008). Like Atcax single mutants, there are no apparent growth defects in Arabidopsis Atccx3 mutant plants, which could be due to functional redundancy. Interestingly, AtCCX3 can transport both monovalent and divalent cations. However, the only divalent cation that can be transported by AtCCX3 is $\mathrm{Mn}^{2+}$. Whether other AtCCXs can translocate $\mathrm{Mn}^{2+}$ remains to be studied.

\section{CDF/MTP family}

The CDF family, also known as MTP, is ubiquitous among all kingdoms of life (Maser et al., 2001; Montanini et al., 2007). The CDFs act as proton antiporters, which efflux metals such as $\mathrm{Zn}^{2+}, \mathrm{Fe}^{2+}, \mathrm{Co}^{2+}, \mathrm{Ni}^{2+}, \mathrm{Cd}^{2+}$, and $\mathrm{Mn}^{2+}$ out of the cytoplasm or into subcellular compartments (Gustin et al., 2011). However, one $\mathrm{CDF}$ protein is reported to be responsible for $\mathrm{Zn}$ uptake into the cytoplasm (Cragg et al., 2002). The plant CDFs are clustered into three functional groups based on phylogenetic analysis: $\mathrm{Zn}-\mathrm{CDFs}$, Fe/Zn-CDFs, and Mn-CDFs (Montanini et al., 2007; Gustin et al., 2011). Metal selectivity of the proteins is inferred from metal transport activity (either confirmed or hypothesized) of the respective members of the three subgroups. Mn-CDFs also contain amino acid residues that may predict metal specificity. The CDFs typically have six transmembrane domains and MnCDFs contain the highly conserved consensus sequence DXXXD (where $X=$ any amino acid) in transmembrane domains 2 and 4 , which is not found in the $\mathrm{Zn}-$ or Fe/Zn-CDFs (Montanini et al., 2007). Studies show that even single point mutations within key structural sites can alter metal ion specificity of the MTPs. For example, single point mutations in AtMTP1 (Podar et al., 2012) and OsMTP1 (Menguer et al., 2013) allow Mn uptake, which is not observed with the wild type protein.

In plants, the CDFs are identified as MTPs due to their role in detoxification of heavy metals (Ricachenevsky et al., 2013). The first characterized Mn-CDF transporter was identified in the Mn hyperaccumulating tropical legume, Stylosanthes hamata (Delhaize et al., 2003). ShMTP8 (previously annotated ShMTP1) can confer $\mathrm{Mn}^{2+}$ tolerance when ectopically expressed in Arabidopsis or yeast by sequestering excess metal in the vacuole. Of the twelve identified CDFs in A. thaliana, there are four in the Mn-CDF subgroup, which are also highly similar to ShMTP8, suggesting similar function. These proteins are AtMTP8, AtMTP9, AtMTP10, AtMTP11. The Mn-CDFs are further divided into subgroup 8 (including AtMTP8 and ShMTP8) and subgroup 9 (including AtMTP9, AtMTP10, and AtMTP11). To date, AtMTP11 is the only functionally characterized Arabidopsis Mn-CDF. Yeast transformed with AtMTP11are more tolerant to $\mathrm{Mn}^{2+}$ (Delhaize et al., 2007; Peiter et al., 2007). In addition, increased $\mathrm{Mn}^{2+}$ dependent proton-transport activity was recorded in yeast microsomal vesicles prepared from yeast expressing AtMTP11 in comparison to vesicles prepared from the control yeast strain (Delhaize et al., 2007). These data further support the role of AtMTP11 as an $\mathrm{Mn}^{2+} / \mathrm{H}^{+}$antiporter. Two independent studies localized AtMTP11 to the pre-vacuolar and Golgi-like compartments. Surprisingly, AtMTP11 is most highly expressed in the leaf hydathodes and the root tip rather than in tissues that typically accumulate excess $\mathrm{Mn}$ such as the trichomes (Peiter et al., 2007). Hydathodes are involved in secretion of water containing salts and metals from the leaf. Therefore, Peiter et al. (2007) hypothesized that AtMTP11 is involved in vesicular trafficking and exocytosis of excess Mn at secretory tissues where Mn will be excreted rather than stored. This hypothesis is supported by the phenotype of both knockout mutants and plants overexpressing AtMTP11. Arabidopsis Atmtp11 mutants are hypersensitive to high $\mathrm{Mn}$ while overexpression lines are hypertolerant to high Mn (Delhaize et al., 2007; Peiter et al., 
2007). Also, the Atmtp11 mutants accumulate more $\mathrm{Mn}$ in the shoot and root, presumably due to their inability to secrete $\mathrm{Mn}$ from tissues (Peiter et al., 2007).

In rice there are five Mn-CDFs: OsMTP8 and OsMTP8.1 from Group 8 and OsMTP9, OsMTP11, and OsMTP11.1 from group 9. Recently, OsMTP8.1 was identified in a screen of rice shoot cDNAs that conferenced Mn tolerance in yeast (Chen et al., 2013). pmr1 yeast mutants expressing OsMTP8.1 also accumulated more Mn. In rice, OsMTP8.1 is mainly expressed in shoots under all conditions tested, and expression increases in response to excess Mn. Osmtp8.1 knockdown and knockout mutants exhibited toxicity symptoms in the presence of elevated Mn and Mn accumulation in the roots and shoot compared to wild type was reduced. The protein is localized to the vacuole, resulting in the hypothesis that OsMTP8.1 is important for Mn detoxification by sequestering $\mathrm{Mn}$ into the vacuole in rice plants.

Two MTP11 orthologs (PtMTP11.1 and PtMTP11.2) in poplar are believed to have a similar function as AtMTP11 due to their localization to Golgi-like compartments and ability to complement Arabidopsis Atmtp11 plants (Peiter et al., 2007). Another study in beets (Beta vulgaris) identified two genes, BmMTP10 and BmMTP11, which were named after their orthologs in A. thaliana. Much like AtMTP11, these proteins are associated with the Golgi and are hypothesized to efflux excess Mn via the secretory pathway. The conservation of Mn-CDF function among multiple plant species supports the importance of these transporters in Mn detoxification and cellular homeostasis.

\section{P-type ATPase family}

The endomembrane system is essential for coordinating ion homeostasis in the cell. Several transporters that localize to the vacuolar membrane are described to facilitate metal uptake and release. However, there are also transporters in other endomembrane compartments that are equally important. Currently, there are two characterized proteins in Arabidopsis, AtECA1 (ER-type calcium ATPases) and AtECA3, which are localized to the ER and Golgi Apparatus, respectively (Liang et al., 1997; Wu et al., 2002; Li et al., 2008; Mills et al., 2008). AtECA1 and AtECA3 function as $\mathrm{Mn}^{2+}$ pumps that remove $\mathrm{Mn}^{2+}$ from the cytosol and deliver it into their respective endomembrane compartment.

The ECAs belong to the $\mathrm{Ca}^{2+}$-ATPase subfamily within the Ptype ATPase superfamily of transporters, which use energy from ATP hydrolysis to catalyze the translocation of cations across membranes (Baxter et al., 2003; Huda et al., 2013). Plant $\mathrm{Ca}^{2+}$ ATPases are categorized into $\mathrm{P}_{2 \mathrm{~A}}$ and $\mathrm{P}_{2 \mathrm{~B}}$-types, both of which are generally described as $\mathrm{Ca}^{2+}$ pumps (Evans and Williams, 1998; Mills et al., 2008). There are four predicted $\mathrm{P}_{2 \mathrm{~A}}$-type ECA proteins in A. thaliana (AtECA1-4) and three in rice (OsECA1-3) (Baxter et al., 2003). $\mathrm{P}_{2 \mathrm{~A}}$-type ATPases show sequence homology to the sarcoplasmic/ER $\mathrm{Ca}^{2+}$-ATPases (SERCA type) found in mammals. SERCAs, PMCAs (plasma membrane $\mathrm{Ca}^{2+}$-ATPases) and SPCAs (secretory pathway $\mathrm{Ca}^{2+}$-ATPases) comprise three distinct subfamilies of $\mathrm{P}_{2}$-type Ca-ATPases in animal cells (Pittman et al., 1999; Mills et al., 2008). PMCAs are homologous to $\mathrm{P}_{2 \mathrm{~B}}$-type PMCAs, while there are no known SPCAs in plants.

Both AtECA1 and AtECA3 are able to restore the growth of pmr1 yeast when Mn is high (Wu et al., 2002; Li et al., 2008;
Mills et al., 2008). Proteomics analysis of Arabidopsis organelles, translational fusions and co-localization with marker proteins supports the ER localization of AtECA1 as well as the Golgi localization of AtECA3 (Wu et al., 2002; Dunkley et al., 2006; Mills et al., 2008; Nikolovski et al., 2012). AtECA1 is expressed in all major organs (especially in the root and flower) where it is believed to play a major role in managing Mn toxicity in the cell (Wu et al., 2002). Atecal mutants appear wild type when grown under standard conditions, yet are smaller and chlorotic in the presence of high Mn. Two different Ateca3 mutants exhibit opposite phenotypes to Mn stress. Ateca3-2 mutants are more susceptible to Mn deficiency (Mills et al., 2008). When grown without $\mathrm{Mn}$, they display stunted growth and leaf chlorosis, which can be rescued by the addition of even trace amounts of Mn. The Ateca3-4 mutant allele is more sensitive to Mn toxicity (Li et al., 2008). The phenotypes of plants carrying these alleles suggest that AtECA3 is important for pumping Mn into the Golgi for proper plant nutrition as well as detoxification via the Golgi compartments. Further investigation is needed to understand the variation between the alleles that uncouples the proposed dual function of the AtECA3 transporter.

There is no evidence that the Arabidopsis AtECA2 or AtECA4 transporters play a role in Mn homeostasis. In fact, Ateca2 mutants appear similar to wild type when grown under high or low Mn (Mills et al., 2008). A tomato ECA, LCA1 (Lycopersicon esculentum $\mathrm{Ca}^{2+}$-ATPases), shows high amino acid sequence similarity to ECA2 (77\%) in comparison to ECA1 and ECA3 (Pittman et al., 1999). LCA1 can also complement the pmr1 yeast mutant, suggesting that it is also an endocompartment-localized $\mathrm{Mn}^{2+}$ pump (Johnson et al., 2009). Additional study of ECAs in A. thaliana, rice and other crop species is required to clarify their role in Mn homeostasis in planta.

\section{VIT/CCC1-like family}

CCC1 $\left(\mathrm{Ca}^{2+}\right.$-sensitive cross complementer 1$)$, which transports Fe and $\mathrm{Mn}$ into the vacuole in yeast (Li et al., 2001), has six orthologs in Arabidopsis referred to as CCC1-like (Rampey et al., 2006; Gollhofer et al., 2011). To date, AtVIT1 is the best characterized CCC1-like transporter and is likely involved in Mn uptake into the vacuole. As hypothesized, cccl mutant yeast, when expressing AtVIT1, could accumulate Mn in the vacuoles (Kim et al., 2006). High-resolution SXRF images of Atvit1 mutant seeds display highly localized $\mathrm{Mn}$ in the Arabidopsis embryo in a pattern identical to that seen in wild type. This is not wholly surprising considering the multitude of transporters that are implicated in Mn transport in the absence of AtVIT1. Therefore, although AtVIT1 is a potential route for Mn transport in planta, it does not appear to be essential for localization of $\mathrm{Mn}$ in the seed. The functional orthologs of AtVIT1 in rice (OsVIT1 and OsVIT2) are localized to the vacuole. They transport Mn, Fe and $\mathrm{Zn}$ in yeast, however physiological studies of mutants suggest that they are only Fe and Zn transporters in planta (Zhang et al., 2012).

\section{CONCLUSIONS AND FUTURE PERSPECTIVES}

$\mathrm{Mn}$, although essential for plant survival, can be toxic to plants. Over the past few decades, several transporter families have been identified that play a role in Mn homeostasis. Interestingly, many 
of the transporters that translocate $\mathrm{Mn}$ have broad specificity for other ions, particularly divalent cations. For example, transporters such as IRT1, originally described as an Fe transporter in the root, can also transport Mn into the plant. In addition, CAX family members along with ECA proteins were originally thought to transport $\mathrm{Ca}$; it was only subsequent research that discovered their roles in Mn transport as well. Despite the advancements in identifying Mn transporters, there is still a lot unknown regarding the molecular mechanisms controlling Mn homeostasis in plants. Many Mn transporters are not differentially regulated at the transcriptional level in response to Mn stress. Further research can explore the possibility that many of the transporters are under post-transcriptional or post-translational control. The degradation of OsNRAMP3 in response to Mn toxicity in rice may be a common mechanism used by plants to tolerate stress conditions (Yamaji et al., 2013).

Further characterization of orthologs of Mn transporters found in A. thaliana in crop species is a necessary step toward agronomic advancement. Research involving identification of genes involved in Mn homeostasis can be exploited to generate plants that are able to thrive in suboptimal soil conditions which would increase crop production and guarantee food security. For example, if we breed plants with high Mn uptake efficiency in the root, we can grow plants in highly alkaline soils where plants usually succumb to Mn deficiency. In conjunction, developing plants with increased Mn storage capability can assist in either soil Mn detoxification or improved growth of plants in acidic soils.

\section{ACKNOWLEDGMENTS}

We thank members of the Guerinot laboratory for helpful discussions; we also thank the many laboratories that have contributed to this field of investigation. In addition we would like to thank Tracy Punshon (Dartmouth College) for critical reading of the manuscript. Work in our laboratory is supported by grants from the National Science Foundation (IOS-091994; DBI 0701119), the National Institutes of Health (RO1 GM 078536), the Department of Energy (DE-FG-2-06ER15809) and the National Institute of Environmental Health Sciences (5 P42 ES007373) to Mary Lou Guerinot and a Fellowship from Sigma Delta Epsilon-Graduate Women in Science to Amanda L. Socha. Amanda L. Socha has also been partially supported by a training grant from the Department of Education's Graduate Assistance in Areas of National Need (GAANN) program. The SXRF image was obtained at The Advanced Photon Source. The Advanced Photon Source, an Office of Science User Facility operated for the U.S. Department of Energy (DOE) Office of Science by Argonne National Laboratory, was supported by the U.S. DOE under Contract No. DE-AC02-06CH11357.

\section{REFERENCES}

Allen, M. D., Kropat, J., Tottey, S., Del Campo, J. A., and Merchant, S. S. (2007). Manganese deficiency in Chlamydomonas results in loss of photosystem II and MnSOD function, sensitivity to peroxides, and secondary phosphorus and iron deficiency. Plant Physiol. 143, 263-277. doi: 10.1104/pp.106.088609

Bartsevich, V. V., and Pakrasi, H. B. (1995). Molecular identification of an $\mathrm{ABC}$ transporter complex for manganese: analysis of a cyanobacterial mutant strain impaired in the photosynthetic oxygen evolution process. EMBO J. 14, 1845-1853.
Bashir, K., Ishimaru, Y., Shimo, H., Nagasaka, S., Fujimoto, M., Takanashi, H., et al. (2011). The rice mitochondrial iron transporter is essential for plant growth. Nat. Commun. 2, 322. doi: 10.1038/ncomms1326

Baxter, I., Muthukumar, B., Park, H. C., Buchner, P., Lahner, B., Danku, J., et al. (2008). Variation in molybdenum content across broadly distributed populations of Arabidopsis thaliana is controlled by a mitochondrial molybdenum transporter (MOT1). PLoS Genet. 4:e1000004. doi: 10.1371/journal.pgen.1000004

Baxter, I., Tchieu, J., Sussman, M. R., Boutry, M., Palmgren, M. G., Gribskov, M., et al. (2003). Genomic comparison of P-type ATPase ion pumps in Arabidopsis and rice. Plant Physiol. 132, 618-628. doi: 10.1104/pp.103.021923

Belouchi, A., Kwan, T., and Gros, P. (1997). Cloning and characterization of the OsNramp family from Oryza sativa, a new family of membrane proteins possibly implicated in the transport of metal ions. Plant Mol. Biol. 33, 1085-1092. doi: 10.1023/A:1005723304911

Bennetzen, J. (2002). The rice genome. Opening the door to comparative plant biology. Science 296, 60-63. doi: 10.1126/science.1071402

Bereczky, Z., Wang, H. Y., Schubert, V., Ganal, M., and Bauer, P. (2003). Differential regulation of NRAMP and IRT metal transporter genes in wild type and iron uptake mutants of tomato. J. Biol. Chem. 278, 24697-24704. doi: 10.1074/jbc.M301365200

Burdette, S. C., Walkup, G. K., Spingler, B., Tsien, R. Y., and Lippard, S. J. (2001). Fluorescent sensors for $\mathrm{Zn}^{(2+)}$ based on a fluorescein platform: synthesis, properties and intracellular distribution. J. Am. Chem. Soc. 123, 7831-7841. doi: 10.1021/ja0100591

Cailliatte, R., Schikora, A., Briat, J. F., Mari, S., and Curie, C. (2010). Highaffinity manganese uptake by the metal transporter NRAMP1 is essential for Arabidopsis growth in low manganese conditions. Plant Cell 22, 904-917. doi: 10.1105/tpc.109.073023

Carter, C., Pan, S., Zouhar, J., Avila, E. L., Girke, T., and Raikhel, N. V. (2004). The vegetative vacuole proteome of Arabidopsis thaliana reveals predicted and unexpected proteins. Plant Cell 16, 3285-3303. doi: 10.1105/tpc.104.027078

Cellier, M., Prive, G., Belouchi, A., Kwan, T., Rodrigues, V., Chia, W., et al. (1995). Nramp defines a family of membrane proteins. Proc. Natl. Acad. Sci. U.S.A. 92, 10089-10093. doi: 10.1073/pnas.92.22.10089

Chen, Z., Fujii, Y., Yamaji, N., Masuda, S., Takemoto, Y., Kamiya, T., et al. (2013). Mn tolerance in rice is mediated by MTP8.1, a member of the cation diffusion facilitator family. J. Exp. Bot. 64, 4375-4387. doi: 10.1093/jxb/ert243

Cheng, N. H., Pittman, J. K., Shigaki, T., and Hirschi, K. D. (2002). Characterization of CAX4, an Arabidopsis $\mathrm{H}^{(+)} /$cation antiporter. Plant Physiol. 128, 1245-1254. doi: 10.1104/pp.010857

Clemens, S., Antosiewicz, D. M., Ward, J. M., Schachtman, D. P., and Schroeder, J. I. (1998). The plant cDNA LCT1 mediates the uptake of calcium and cadmium in yeast. Proc. Natl. Acad. Sci. U.S.A. 95, 12043-12048. doi: 10.1073/pnas.95.20.12043

Cohen, C. K., Garvin, D. F., and Kochian, L. V. (2004). Kinetic properties of a micronutrient transporter from Pisum sativum indicate a primary function in Fe uptake from the soil. Planta 218, 784-792. doi: 10.1007/s00425-003-1156-7

Connolly, E. L., Fett, J. P., and Guerinot, M. L. (2002). Expression of the IRT1 metal transporter is controlled by metals at the levels of transcript and protein accumulation. Plant Cell 14, 1347-1357. doi: 10.1105/tpc.001263

Connorton, J. M., Webster, R. E., Cheng, N., and Pittman, J. K. (2012). Knockout of multiple Arabidopsis cation $/ \mathrm{H}^{(+)}$exchangers suggests isoform-specific roles in metal stress response, germination and seed mineral nutrition. PLoS ONE 7:e47455. doi: 10.1371/journal.pone.0047455

Conte, S. S., Chu, H. H., Rodriguez, D. C., Punshon, T., Vasques, K. A., Salt, D. E., et al. (2013). Arabidopsis thaliana Yellow Stripe1-Like4 and Yellow Stripe1Like6 localize to internal cellular membranes and are involved in metal ion homeostasis. Front. Plant Sci. 4:283. doi: 10.3389/fpls.2013.00283

Cragg, R. A., Christie, G. R., Phillips, S. R., Russi, R. M., Kury, S., Mathers, J. C., et al. (2002). A novel zinc-regulated human zinc transporter, hZTL1, is localized to the enterocyte apical membrane. J. Biol. Chem. 277, 22789-22797. doi: 10.1074/jbc.M200577200

Culotta, V. C., Yang, M., and Hall, M. D. (2005). Manganese transport and trafficking: lessons learned from Saccharomyces cerevisiae. Eukaryot. Cell 4, 1159-1165. doi: 10.1128/EC.4.7.1159-1165.2005

Curie, C., Alonso, J. M., Le Jean, M., Ecker, J. R., and Briat, J. F. (2000). Involvement of NRAMP1 from Arabidopsis thaliana in iron transport. Biochem. J. 347, 749-755. doi: 10.1042/0264-6021:3470749 
Curie, C., Cassin, G., Couch, D., Divol, F., Higuchi, K., Le Jean, M., et al. (2009). Metal movement within the plant: contribution of nicotianamine and yellow stripe 1-like transporters. Ann. Bot. 103, 1-11. doi: 10.1093/aob/mcn207

Curie, C., Panaviene, Z., Loulergue, C., Dellaporta, S. L., Briat, J. F., and Walker, E. L. (2001). Maize yellow stripel encodes a membrane protein directly involved in Fe(III) uptake. Nature 409, 346-349. doi: 10.1038/35053080

Dancis, A., Haile, D., Yuan, D. S., and Klausner, R. D. (1994). The Saccharomyces cerevisiae copper transport protein (Ctrlp). Biochemical characterization, regulation by copper, and physiologic role in copper uptake. J. Biol. Chem. 269, 25660-25667.

Delhaize, E., Gruber, B. D., Pittman, J. K., White, R. G., Leung, H., Miao, Y., et al. (2007). A role for the AtMTP11 gene of Arabidopsis in manganese transport and tolerance. Plant J. 51, 198-210. doi: 10.1111/j.1365-313X.2007.03138.x

Delhaize, E., Kataoka, T., Hebb, D. M., White, R. G., and Ryan, P. R. (2003). Genes encoding proteins of the cation diffusion facilitator family that confer manganese tolerance. Plant Cell 15, 1131-1142. doi: 10.1105/tpc.009134

Didonato, R. J. Jr., Roberts, L. A., Sanderson, T., Eisley, R. B., and Walker, E. L. (2004). Arabidopsis Yellow Stripe-Like2 (YSL2): a metal-regulated gene encoding a plasma membrane transporter of nicotianamine-metal complexes. Plant J. 39, 403-414. doi: 10.1111/j.1365-313X.2004.02128.x

Divol, F., Couch, D., Conejero, G., Roschzttardtz, H., Mari, S., and Curie, C. (2013). The Arabidopsis Yellow Stripe LIKE4 and 6 transporters control iron release from the chloroplast. Plant Cell 25, 1040-1055. doi: 10.1105/tpc.112.107672

Dix, D. R., Bridgham, J. T., Broderius, M. A., Byersdorfer, C. A., and Eide, D. J. (1994). The FET4 gene encodes the low affinity $\mathrm{Fe}(\mathrm{II})$ transport protein of Saccharomyces cerevisiae. J. Biol. Chem. 269, 26092-26099.

Donner, E., Punshon, T., Guerinot, M. L., and Lombi, E. (2012). Functional characterisation of metal(loid) processes in planta through the integration of synchrotron techniques and plant molecular biology. Anal. Bioanal. Chem. 402, 3287-3298. doi: 10.1007/s00216-011-5624-9

Dunkley, T. P., Hester, S., Shadforth, I. P., Runions, J., Weimar, T., Hanton, S. L., et al. (2006). Mapping the Arabidopsis organelle proteome. Proc. Natl. Acad. Sci. U.S.A. 103, 6518-6523. doi: 10.1073/pnas.0506958103

Durr, G., Strayle, J., Plemper, R., Elbs, S., Klee, S. K., Catty, P., et al. (1998). The medial-Golgi ion pump Pmrl supplies the yeast secretory pathway with $\mathrm{Ca}^{2+}$ and $\mathrm{Mn}^{2+}$ required for glycosylation, sorting, and endoplasmic reticulum-associated protein degradation. Mol. Biol. Cell 9, 1149-1162. doi: 10.1091/mbc.9.5.1149

Eckhardt, U., Mas Marques, A., and Buckhout, T. J. (2001). Two iron-regulated cation transporters from tomato complement metal uptake-deficient yeast mutants. Plant Mol. Biol. 45, 437-448. doi: 10.1023/A:1010620012803

Edmond, C., Shigaki, T., Ewert, S., Nelson, M. D., Connorton, J. M., Chalova, V., et al. (2009). Comparative analysis of CAX2-like cation transporters indicates functional and regulatory diversity. Biochem J. 418, 145-154. doi: 10.1042/BJ20081814

Eide, D., Broderius, M., Fett, J., and Guerinot, M. L. (1996). A novel iron-regulated metal transporter from plants identified by functional expression in yeast. Proc. Natl. Acad. Sci. U.S.A. 93, 5624-5628. doi: 10.1073/pnas.93.11.5624

Emery, L., Whelan, S., Hirschi, K. D., and Pittman, J. K. (2012). Protein phylogenetic analysis of $\mathrm{Ca}^{(2+)} /$ cation Antiporters and insights into their evolution in plants. Front. Plant Sci. 3:1. doi: 10.3389/fpls.2012.00001

Erbasol, I., Bozdag, G. O., Koc, A., Pedas, P., and Karakaya, H. C. (2013). Characterization of two genes encoding metal tolerance proteins from Beta vulgaris subspecies maritima that confers manganese tolerance in yeast. Biometals 26, 795-804. doi: 10.1007/s10534-013-9658-7

Evans, D. E., and Williams, L. E. (1998). P-type calcium ATPases in higher plants biochemical, molecular and functional properties. Biochim. Biophys. Acta 1376, 1-25. doi: 10.1016/S0304-4157(97)00009-9

Fecht-Christoffers, M. M., Braun, H. P., Lemaitre-Guillier, C., Vandorsselaer, A., and Horst, W. J. (2003). Effect of manganese toxicity on the proteome of the leaf apoplast in cowpea. Plant Physiol. 133, 1935-1946. doi: 10.1104/pp.103.029215

Fernando, D. R., Bakkaus, E. J., Perrier, N., Baker, A. J., Woodrow, I. E., Batianoff, G. N., et al. (2006a). Manganese accumulation in the leaf mesophyll of four tree species: a PIXE/EDAX localization study. New Phytol. 171, 751-757. doi: 10.1111/j.1469-8137.2006.01783.x

Fernando, D. R., Batianoff, G. N., Baker, A. J., and Woodrow, I. E. (2006b). In vivo localization of manganese in the hyperaccumulator Gossia bidwillii (Benth.) N. Snow \& Guymer (Myrtaceae) by cryo-SEM/EDAX. Plant Cell Environ. 29, 1012-1020. doi: 10.1111/j.1365-3040.2006.01498.x
Fernando, D. R., Marshall, A., Baker, A. J., and Mizuno, T. (2013). Microbeam methodologies as powerful tools in manganese hyperaccumulation research: present status and future directions. Front. Plant Sci. 4:319. doi: 10.3389/fpls.2013.00319

Fernando, D. R., Mizuno, T., Woodrow, I. E., Baker, A. J., and Collins, R. N. (2010). Characterization of foliar manganese (Mn) in Mn (hyper)accumulators using X-ray absorption spectroscopy. New Phytol. 188, 1014-1027. doi: 10.1111/j.1469-8137.2010.03431.x

Fernando, D. R., Woodrow, I. E., Jaffre, T., Dumontet, V., Marshall, A. T., and Baker, A. J. (2008). Foliar manganese accumulation by Maytenus founieri (Celastraceae) in its native New Caledonian habitats: populational variation and localization by X-ray microanalysis. New Phytol. 177, 178-185. doi: 10.1111/j.1469-8137.2007.02253.x

Geszvain, K., Butterfield, C., Davis, R. E., Madison, A. S., Lee, S. W., Parker, D. L., et al. (2012). The molecular biogeochemistry of manganese(II) oxidation. Biochem. Soc. Trans. 40, 1244-1248. doi: 10.1042/BST20120229

Gollhofer, J., Shlawicke, C., Jungnick, N., Schmidt, W., and Buckhout, T. J. (2011). Members of a small family of nodulin-like genes are regulated under iron deficiency in roots of Arabidopsis thaliana. Plant Physiol. Biochem. 49, 557-564. doi: 10.1016/j.plaphy.2011.02.011

Goussias, C., Boussac, A., and Rutherford, A. W. (2002). Photosystem II and photosynthetic oxidation of water: an overview. Philos. Trans. R. Soc. Lond. B Biol. Sci. 357, 1369-1381. discussion: 1419-1320. doi: 10.1098/rstb.2002.1134

Grotz, N., Fox, T., Connolly, E., Park, W., Guerinot, M. L., and Eide, D. (1998). Identification of a family of zinc transporter genes from Arabidopsis that respond to zinc deficiency. Proc. Natl. Acad. Sci. U.S.A. 95, 7220-7224. doi: $10.1073 /$ pnas.95.12.7220

Guerinot, M. L. (2000). The ZIP family of metal transporters. Biochim. Biophys. Acta 1465, 190-198. doi: 10.1016/S0005-2736(00)00138-3

Gustin, J. L., Zanis, M. J., and Salt, D. E. (2011). Structure and evolution of the plant cation diffusion facilitator family of ion transporters. BMC Evol. Biol. 11:76. doi: 10.1186/1471-2148-11-76

Haydon, M. J., and Cobbett, C. S. (2007). Transporters of ligands for essential metal ions in plants. New Phytol. 174, 499-506. doi: 10.1111/j.1469-8137.2007.02051.x

He, Z. L., Yang, X. E., and Stoffella, P. J. (2005). Trace elements in agroecosystems and impacts on the environment. J. Trace Elem. Med. Biol. 19, 125-140. doi: 10.1016/j.jtemb.2005.02.010

Hebbern, C. A., Laursen, K. H., Ladegaard, A. H., Schmidt, S. B., Pedas, P., Bruhn, D., et al. (2009). Latent manganese deficiency increases transpiration in barley (Hordeum vulgare). Physiol. Plant 135, 307-316. doi: 10.1111/j.13993054.2008.01188.x

Hirschi, K. D., Korenkov, V. D., Wilganowski, N. L., and Wagner, G. J. (2000). Expression of arabidopsis CAX2 in tobacco. Altered metal accumulation and increased manganese tolerance. Plant Physiol. 124, 125-133. doi: 10.1104/pp.124.1.125

Horst, W. J., and Maier P. (1999). "Compartmentalization of manganese in the vacuoles and in the apoplast of leaves in relation to genotypic manganese leaf-tissue tolerance in Vigna unguiculata (L.) Walp," in Plant Nutrition-Molecular Biology and Genetics, eds G. Gissel-Nielsen and A. Jensen (Dordrecht: Kluwer Academic Publishers), 222-234.

Huda, K. M., Banu, M. S., Tuteja, R., and Tuteja, N. (2013). Global calcium transducer P-type $\mathrm{Ca}^{(2)(+)}$-ATPases open new avenues for agriculture by regulating stress signalling. J. Exp. Bot. 64, 3099-3109. doi: 10.1093/jxb/ert182

Ishimaru, Y., Takahashi, R., Bashir, K., Shimo, H., Senoura, T., Sugimoto, K., et al. (2012). Characterizing the role of rice NRAMP5 in manganese, iron and cadmium transport. Sci. Rep. 2:286. doi: 10.1038/srep00286

Jakubovics, N. S., and Jenkinson, H. F. (2001). Out of the iron age: new insights into the critical role of manganese homeostasis in bacteria. Microbiology 147, 1709-1718.

Jaquinod, M., Villiers, F., Kieffer-Jaquinod, S., Hugouvieux, V., Bruley, C., Garin, J., et al. (2007). A proteomics dissection of Arabidopsis thaliana vacuoles isolated from cell culture. Mol. Cell Proteomics 6, 394-412. doi: 10.1074/mcp.M600250MCP200

Jensen, L. T., Ajua-Alemanji, M., and Culotta, V. C. (2003). The Saccharomyces cerevisiae high affinity phosphate transporter encoded by PHO84 also functions in manganese homeostasis. J. Biol. Chem. 278, 42036-42040. doi: 10.1074/jbc.M307413200

Jiang, W. (2006). Mn use efficiency in different wheat cultivars. Environ. Exp. Bot. 57, 41-50. doi: 10.1016/j.envexpbot.2005.04.008 
Johnson, N. A., Liu, F., Weeks, P. D., Hentzen, A. E., Kruse, H. P., Parker, J. J., et al. (2009). A tomato ER-type $\mathrm{Ca}^{2+}$-ATPase, LCA1, has a low thapsigarginsensitivity and can transport manganese. Arch. Biochem. Biophys. 481, 157-168. doi: 10.1016/j.abb.2008.11.010

Kaiser, B. N., Moreau, S., Castelli, J., Thomson, R., Lambert, A., Bogliolo, S., et al. (2003). The soybean NRAMP homologue, GmDMT1, is a symbiotic divalent metal transporter capable of ferrous iron transport. Plant J. 35, 295-304. doi: 10.1046/j.1365-313X.2003.01802.x

Kamiya, T., Akahori, T., and Maeshima, M. (2005). Expression profile of the genes for rice cation $/ \mathrm{H}^{+}$exchanger family and functional analysis in yeast. Plant Cell Physiol. 46, 1735-1740. doi: 10.1093/pcp/pci173

Kamiya, T., and Maeshima, M. (2004). Residues in internal repeats of the rice cation $/ \mathrm{H}^{+}$exchanger are involved in the transport and selection of cations. J. Biol. Chem. 279, 812-819. doi: 10.1074/jbc.M309726200

Kiegle, E., Gilliham, M., Haseloff, J., and Tester, M. (2000). Hyperpolarisationactivated calcium currents found only in cells from the elongation zone of Arabidopsis thaliana roots. Plant J. 21, 225-229. doi: 10.1046/j.1365313x.2000.00659.x

Kim, S. A., Punshon, T., Lanzirotti, A., Li, L., Alonso, J. M., Ecker, J. R., et al. (2006). Localization of iron in Arabidopsis seed requires the vacuolar membrane transporter VIT1. Science 314, 1295-1298. doi: 10.1126/science.1132563

Koike, S., Inoue, H., Mizuno, D., Takahashi, M., Nakanishi, H., Mori, S., et al. (2004). OsYSL2 is a rice metal-nicotianamine transporter that is regulated by iron and expressed in the phloem. Plant J. 39, 415-424. doi: 10.1111/j.1365313X.2004.02146.x

Korenkov, V., Hirschi, K., Crutchfield, J. D., and Wagner, G. J. (2007). Enhancing tonoplast $\mathrm{Cd} / \mathrm{H}$ antiport activity increases $\mathrm{Cd}, \mathrm{Zn}$, and $\mathrm{Mn}$ tolerance, and impacts root/shoot Cd partitioning in Nicotiana tabacum L. Planta 226, 1379-1387. doi: 10.1007/s00425-007-0577-0

Korshunova, Y. O., Eide, D., Clark, W. G., Guerinot, M. L., and Pakrasi, H. B. (1999). The IRT1 protein from Arabidopsis thaliana is a metal transporter with a broad substrate range. Plant Mol. Biol. 40, 37-44. doi: 10.1023/A:1026438615520

Kramer, U. (2010). Metal hyperaccumulation in plants. Annu. Rev. Plant Biol. 61, 517-534. doi: 10.1146/annurev-arplant-042809-112156

Krieger, A., Rutherford, A. W., Vass, I., and Hideg, E. (1998). Relationship between activity, D1 loss, and Mn binding in photoinhibition of photosystem II. Biochemistry 37, 16262-16269. doi: 10.1021/bi981243v

Lanquar, V., Lelievre, F., Bolte, S., Hames, C., Alcon, C., Neumann, D., et al. (2005). Mobilization of vacuolar iron by AtNRAMP3 and AtNRAMP4 is essential for seed germination on low iron. EMBO J. 24, 4041-4051. doi: 10.1038/sj.emboj.7600864

Lanquar, V., Ramos, M. S., Lelievre, F., Barbier-Brygoo, H., Krieger-Liszkay, A., Kramer, U., et al. (2010). Export of vacuolar manganese by AtNRAMP3 and AtNRAMP4 is required for optimal photosynthesis and growth under manganese deficiency. Plant Physiol. 152, 1986-1999. doi: 10.1104/pp.109.150946

Lee, S., Jeong, H. J., Kim, S. A., Lee, J., Guerinot, M. L., and An, G. (2010). OsZIP5 is a plasma membrane zinc transporter in rice. Plant Mol. Biol. 73, 507-517. doi: 10.1007/s11103-010-9637-0

Leitenmaier, B., and Kupper, H. (2013). Compartmentation and complexation of metals in hyperaccumulator plants. Front. Plant Sci. 4:374. doi: 10.3389/fpls.2013.00374

Li, L., Chen, O. S., McVey Ward, D., and Kaplan, J. (2001). CCC1 is a transporter that mediates vacuolar iron storage in yeast. J. Biol. Chem. 276, 29515-29519. doi: 10.1074/jbc.M103944200

Li, X., Chanroj, S., Wu, Z., Romanowsky, S. M., Harper, J. F., and Sze, H. (2008). A distinct endosomal $\mathrm{Ca}^{2+} / \mathrm{Mn}^{2+}$ pump affects root growth through the secretory process. Plant Physiol. 147, 1675-1689. doi: 10.1104/pp.108.119909

Liang, F., Cunningham, K. W., Harper, J. F., and Sze, H. (1997). ECAl complements yeast mutants defective in $\mathrm{Ca}^{2+}$ pumps and encodes an endoplasmic reticulumtype $\mathrm{Ca}^{2+}$-ATPase in Arabidopsis thaliana. Proc. Natl. Acad. Sci. U.S.A. 94, 8579-8584. doi: 10.1073/pnas.94.16.8579

Lopez-Millan, A. F., Ellis, D. R., and Grusak, M. A. (2004). Identification and characterization of several new members of the ZIP family of metal ion transporters in Medicago truncatula. Plant Mol. Biol. 54, 583-596. doi: 10.1023/B:PLAN.0000038271.96019.aa

Lovley, D. R., Ueki, T., Zhang, T., Malvankar, N. S., Shrestha, P. M., Flanagan, K. A., et al. (2011). Geobacter: the microbe electric's physiology, ecology, and practical applications. Adv. Microb. Physiol. 59, 1-100. doi: 10.1016/B978-0-12-3876614.00004-5

Lynch, J. P., and St. Clair, S. B. (2004). Mineral stress: the missing link in understanding how global climate change will affect plants in real world soils. Field Crop Res. 90, 101-115. doi: 10.1016/j.fcr.2004.07.008

Marschner, P. (2012). Marschner's Mineral Nutrition of Higher Plants. Boston, MA: Academic Press.

Marshall, J., Corzo, A., Leigh, R. A., and Sanders, D. (1994). Membrane potentialdependent calcium transport in right-side-out plasma membrane vesicles from Zea mays L. roots. Plant J. 5, 683-694. doi: 10.1111/j.1365-313X.1994.00683.x

Martinez-Finley, E. J., Gavin, C. E., Aschner, M., and Gunter, T. E. (2013). Manganese neurotoxicity and the role of reactive oxygen species. Free Radic. Biol. Med. 62, 65-75. doi: 10.1016/j.freeradbiomed.2013.01.032

Maser, P., Thomine, S., Schroeder, J. I., Ward, J. M., Hirschi, K., Sze, H., et al. (2001). Phylogenetic relationships within cation transporter families of Arabidopsis. Plant Physiol. 126, 1646-1667. doi: 10.1104/pp.126.4.1646

Mei, H., Cheng, N. H., Zhao, J., Park, S., Escareno, R. A., Pittman, J. K., et al. (2009). Root development under metal stress in Arabidopsis thaliana requires the $\mathrm{H}^{+}$/cation antiporter CAX4. New Phytol. 183, 95-105. doi: 10.1111/j.14698137.2009.02831.x

Menguer, P. K., Farthing, E., Peaston, K. A., Ricachenevsky, F. K., Fett, J. P., and Williams, L. E. (2013). Functional analysis of the rice vacuolar zinc transporter OsMTP1. J. Exp. Bot. 64, 2871-2883. doi: 10.1093/jxb/ert136

Millaleo, R., Reyes-Diaz, M., Alberdi, M., Ivanov, A. G., Krol, M., and Huner, N. P. (2013). Excess manganese differentially inhibits photosystem I versus II in Arabidopsis thaliana. J. Exp. Bot. 64, 343-354. doi: 10.1093/jxb/ers339

Miller, E. W., He, Q., and Chang, C. J. (2008). Preparation and use of Leadfluor-1, a synthetic fluorophore for live-cell lead imaging. Nat. Protoc. 3, 777-783. doi: 10.1038/nprot.2008.43

Miller, E. W., Zeng, L., Domaille, D. W., and Chang, C. J. (2006). Preparation and use of Coppersensor-1, a synthetic fluorophore for live-cell copper imaging. Nat. Protoc. 1, 824-827. doi: 10.1038/nprot.2006.140

Mills, R. F., Doherty, M. L., Lopez-Marques, R. L., Weimar, T., Dupree, P., Palmgren, M. G., et al. (2008). ECA3, a Golgi-localized P2A-type ATPase, plays a crucial role in manganese nutrition in Arabidopsis. Plant Physiol. 146, 116-128. doi: 10.1104/pp.107.110817

Milner, M. J., Seamon, J., Craft, E., and Kochian, L. V. (2013). Transport properties of members of the ZIP family in plants and their role in $\mathrm{Zn}$ and Mn homeostasis. J. Exp. Bot. 64, 369-381. doi: 10.1093/jxb/ers315

Mizuno, T., Usui, K., Horie, K., Nosaka, S., Mizuno, N., and Obata, H. (2005). Cloning of three ZIP/Nramp transporter genes from a Ni hyperaccumulator plant Thlaspi japonicum and their $\mathrm{Ni}^{2+}$-transport abilities. Plant Physiol. Biochem. 43, 793-801. doi: 10.1016/j.plaphy.2005.07.006

Montanini, B., Blaudez, D., Jeandroz, S., Sanders, D., and Chalot, M. (2007). Phylogenetic and functional analysis of the Cation Diffusion Facilitator (CDF) family: improved signature and prediction of substrate specificity. BMC Genomics 8:107. doi: 10.1186/1471-2164-8-107

Morris, J., Tian, H., Park, S., Sreevidya, C. S., Ward, J. M., and Hirschi, K. D. (2008). AtCCX3 is an Arabidopsis endomembrane $\mathrm{H}^{+}$-dependent $\mathrm{K}^{+}$transporter. Plant Physiol. 148, 1474-1486. doi: 10.1104/pp.108.118810

Nevo, Y., and Nelson, N. (2006). The NRAMP family of metal-ion transporters. Biochim. Biophys. Acta 1763, 609-620. doi: 10.1016/j.bbamcr.2006.05.007

Nickelsen, J., and Rengstl, B. (2013). Photosystem II assembly: from cyanobacteria to plants. Annu. Rev. Plant Biol. 64, 609-635. doi: 10.1146/annurev-arplant050312-120124

Nikolovski, N., Rubtsov, D., Segura, M. P., Miles, G. P., Stevens, T. J., Dunkley, T. P., et al. (2012). Putative glycosyltransferases and other plant Golgi apparatus proteins are revealed by LOPIT proteomics. Plant Physiol. 160, 1037-1051. doi: 10.1104/pp.112.204263

Oomen, R. J., Wu, J., Lelievre, F., Blanchet, S., Richaud, P., Barbier-Brygoo, H., et al. (2009). Functional characterization of NRAMP3 and NRAMP4 from the metal hyperaccumulator Thlaspi caerulescens. New Phytol. 181, 637-650. doi: 10.1111/j.1469-8137.2008.02694.x

Palmer, C. M., and Guerinot, M. L. (2009). Facing the challenges of Cu, Fe and $\mathrm{Zn}$ homeostasis in plants. Nat. Chem. Biol. 5, 333-340. doi: 10.1038/nchembio.166

Papp-Wallace, K. M., and Maguire, M. E. (2006). Manganese transport and the role of manganese in virulence. Annu. Rev. Microbiol. 60, 187-209. doi: 10.1146/annurev.micro.60.080805.142149 
Pedas, P., Ytting, C. K., Fuglsang, A. T., Jahn, T. P., Schjoerring, J. K., and Husted, S. (2008). Manganese efficiency in barley: identification and characterization of the metal ion transporter HvIRT1. Plant Physiol. 148, 455-466. doi: 10.1104/pp.108.118851

Peiter, E., Montanini, B., Gobert, A., Pedas, P., Husted, S., Maathuis, F. J., et al. (2007). A secretory pathway-localized cation diffusion facilitator confers plant manganese tolerance. Proc. Natl. Acad. Sci. U.S.A. 104, 8532-8537. doi: $10.1073 /$ pnas.0609507104

Pittman, J. K. (2005). Managing the manganese: molecular mechanisms of manganese transport and homeostasis. New Phytol. 167, 733-742. doi: 10.1111/j.1469-8137.2005.01453.x

Pittman, J. K., Mills, R. F., O'connor, C. D., and Williams, L. E. (1999). Two additional type IIA $\mathrm{Ca}^{(2+)}$-ATPases are expressed in Arabidopsis thaliana: evidence that type IIA sub-groups exist. Gene 236, 137-147. doi: 10.1016/S03781119(99)00242-5

Pittman, J. K., Shigaki, T., Marshall, J. L., Morris, J. L., Cheng, N. H., and Hirschi, K. D. (2004). Functional and regulatory analysis of the Arabidopsis thaliana CAX2 cation transporter. Plant Mol. Biol. 56, 959-971. doi: 10.1007/s11103-0046446-3

Podar, D., Scherer, J., Noordally, Z., Herzyk, P., Nies, D., and Sanders, D. (2012). Metal selectivity determinants in a family of transition metal transporters. J. Biol. Chem. 287, 3185-3196. doi: 10.1074/jbc.M111.305649

Punshon, T., Hirschi, K., Yang, J., Lanzirotti, A., Lai, B., and Guerinot, M. L. (2012). The role of CAX1 and CAX3 in elemental distribution and abundance in Arabidopsis seed. Plant Physiol. 158, 352-362. doi: 10.1104/pp.111. 184812

Punshon, T., Ricachenevsky, F. K., Hindt, M. N., Socha, A. L., and Zuber, H. (2013). Methodological approaches for using synchrotron X-ray fluorescence (SXRF) imaging as a tool in ionomics: examples from Arabidopsis thaliana. Metallomics 5, 1133-1145. doi: 10.1039/c3mt00120b

Rampey, R. A., Baldridge, M. T., Farrow, D. C., Bay, S. N., and Bartel, B. (2013). Compensatory mutations in predicted metal transporters modulate auxin conjugate responsiveness in Arabidopsis. G3 3, 131-141. doi: $10.1534 / \mathrm{g} 3.112 .004655$

Rampey, R. A., Woodward, A. W., Hobbs, B. N., Tierney, M. P., Lahner, B., Salt, D. E., et al. (2006). An Arabidopsis basic helix-loop-helix leucine zipper protein modulates metal homeostasis and auxin conjugate responsiveness. Genetics 174, 1841-1857. doi: 10.1534/genetics.106.061044

Reddi, A. R., Jensen, L. T., and Culotta, V. C. (2009). Manganese homeostasis in Saccharomyces cerevisiae. Chem. Rev. 109, 4722-4732. doi: 10.1021/cr90 $0031 \mathrm{u}$

Rengel, Z. (2000). Manganese uptake and transport in plants. Met. Ions Biol. Syst. $37,57-87$.

Ricachenevsky, F. K., Menguer, P. K., Sperotto, R. A., Williams, L. E., and Fett, J. P. (2013). Roles of plant metal tolerance proteins (MTP) in metal storage and potential use in biofortification strategies. Front. Plant Sci. 4:144. doi: 10.3389/fpls.2013.00144

Roberts, L. A., Pierson, A. J., Panaviene, Z., and Walker, E. L. (2004). Yellow stripe1. Expanded roles for the maize iron-phytosiderophore transporter. Plant Physiol. 135, 112-120. doi: 10.1104/pp.103.037572

Rogers, E. E., Eide, D. J., and Guerinot, M. L. (2000). Altered selectivity in an Arabidopsis metal transporter. Proc. Natl. Acad. Sci. U.S.A. 97, 12356-12360. doi: 10.1073/pnas.210214197

Rudolph, H. K., Antebi, A., Fink, G. R., Buckley, C. M., Dorman, T. E., Levitre, J., et al. (1989). The yeast secretory pathway is perturbed by mutations in PMR1, a member of a Ca ${ }^{2+}$ ATPase family. Cell 58, 133-145. doi: 10.1016/00928674(89)90410-8

Salt, D. E., Smith, R. D., and Raskin, I. (1998). Phytoremediation. Annu. Rev. Plant Physiol. Plant Mol. Biol. 49, 643-668. doi: 10.1146/annurev.arplant.49.1.643

Salvador, V. H., Lima, R. B., Dos Santos, W. D., Soares, A. R., Bohm, P. A., Marchiosi, R., et al. (2013). Cinnamic acid increases lignin production and inhibits soybean root growth. PLOS ONE 8:e69105. doi: 10.1371/journal.pone.0069105

Sasaki, A., Yamaji, N., Xia, J., and Ma, J. F. (2011). OsYSL6 is involved in the detoxification of excess manganese in rice. Plant Physiol. 157, 1832-1840. doi: 10.1104/pp.111.186031

Sasaki, A., Yamaji, N., Yokosho, K., and Ma, J. F. (2012). Nramp5 is a major transporter responsible for manganese and cadmium uptake in rice. Plant Cell 24, 2155-2167. doi: 10.1105/tpc.112.096925
Schaaf, G., Catoni, E., Fitz, M., Schwacke, R., Von Wiren, N., and Frommer, W. B. (2002). A putative role for the vacuolar calcium/manganese proton antiporter AtCAX2 in heavy metal detoxification. Plant Biol. 4, 612-618. doi: 10.1055/s2002-35432

Schaaf, G., Ludewig, U., Erenoglu, B. E., Mori, S., Kitahara, T., and Von Wiren, N. (2004). ZmYS1 functions as a proton-coupled symporter for phytosiderophoreand nicotianamine-chelated metals. J. Biol. Chem. 279, 9091-9096. doi: 10.1074/jbc.M311799200

Schnell Ramos, M., Khodja, H., Mary, V., and Thomine, S. (2013). Using muPIXE for quantitative mapping of metal concentration in Arabidopsis thaliana seeds. Front. Plant Sci. 4:168. doi: 10.3389/fpls.2013.00168

Schroeder, J. I., Delhaize, E., Frommer, W. B., Guerinot, M. L., Harrison, M. J., Herrera-Estrella, L., et al. (2013). Using membrane transporters to improve crops for sustainable food production. Nature 497, 60-66. doi: 10.1038 /nature11909

Shigaki, T., and Hirschi, K. D. (2006). Diverse functions and molecular properties emerging for CAX cation/ $\mathrm{H}^{+}$exchangers in plants. Plant Biol. 8, 419-429. doi: 10.1055/s-2006-923950

Shigaki, T., Pittman, J. K., and Hirschi, K. D. (2003). Manganese specificity determinants in the Arabidopsis metal/ $\mathrm{H}^{+}$antiporter CAX2. J. Biol. Chem. 278, 6610-6617. doi: 10.1074/jbc.M209952200

Shigaki, T., Rees, I., Nakhleh, L., and Hirschi, K. D. (2006). Identification of three distinct phylogenetic groups of CAX cation/proton antiporters. J. Mol. Evol. 63, 815-825. doi: 10.1007/s00239-006-0048-4

Supek, F., Supekova, L., Nelson, H., and Nelson, N. (1996). A yeast manganese transporter related to the macrophage protein involved in conferring resistance to mycobacteria. Proc. Natl. Acad. Sci. U.S.A. 93, 5105-5110. doi: 10.1073/pnas.93.10.5105

Thomine, S., Lelievre, F., Debarbieux, E., Schroeder, J. I., and Barbier-Brygoo, H. (2003). AtNRAMP3, a multispecific vacuolar metal transporter involved in plant responses to iron deficiency. Plant J. 34, 685-695. doi: 10.1046/j.1365313X.2003.01760.x

Thomine, S., Wang, R., Ward, J. M., Crawford, N. M., and Schroeder, J. I. (2000). Cadmium and iron transport by members of a plant metal transporter family in Arabidopsis with homology to Nramp genes. Proc. Natl. Acad. Sci. U.S.A. 97, 4991-4996. doi: 10.1073/pnas.97.9.4991

Ueno, D., Yamaji, N., and Ma, J. F. (2009). Further characterization of ferricphytosiderophore transporters ZmYS1 and HvYS1 in maize and barley. J. Exp. Bot. 60, 3513-3520. doi: 10.1093/jxb/erp191

Vert, G., Grotz, N., Dedaldechamp, F., Gaymard, F., Guerinot, M. L., Briat, J. F., et al. (2002). IRT1, an Arabidopsis transporter essential for iron uptake from the soil and for plant growth. Plant Cell 14, 1223-1233. doi: 10.1105/tpc.001388

Very, A. A., and Davies, J. M. (2000). Hyperpolarization-activated calcium channels at the tip of Arabidopsis root hairs. Proc. Natl. Acad. Sci. U.S.A. 97, 9801-9806. doi: $10.1073 /$ pnas. 160250397

Von Wiren, N., Mori, S., Marschner, H., and Romheld, V. (1994). Iron inefficiency in maize mutant $y s 1$ (Zea mays L. cv Yellow-Stripe) is caused by a defect in uptake of iron phytosiderophores. Plant Physiol. 106, 71-77.

Waters, B. M., Chu, H. H., Didonato, R. J., Roberts, L. A., Eisley, R. B., Lahner, B., et al. (2006). Mutations in Arabidopsis yellow stripe-like1 and yellow stripelike3 reveal their roles in metal ion homeostasis and loading of metal ions in seeds. Plant Physiol. 141, 1446-1458. doi: 10.1104/pp.106.082586

White, P. J., Bowen, H. C., Demidchik, V., Nichols, C., and Davies, J. M. (2002). Genes for calcium-permeable channels in the plasma membrane of plant root cells. Biochim. Biophys. Acta 1564, 299-309. doi: 10.1016/S0005-2736(02) 00509-6

Wu, Z., Liang, F., Hong, B., Young, J. C., Sussman, M. R., Harper, J. F., et al. (2002). An endoplasmic reticulum-bound $\mathrm{Ca}^{(2+)} / \mathrm{Mn}^{(2+)}$ pump, ECA1, supports plant growth and confers tolerance to $\mathrm{Mn}^{(2+)}$ stress. Plant Physiol. 130, 128-137. doi: 10.1104/pp.004440

Wymer, C. L., Bibikova, T. N., and Gilroy, S. (1997). Cytoplasmic free calcium distributions during the development of root hairs of Arabidopsis thaliana. Plant J. 12, 427-439. doi: 10.1046/j.1365-313X.1997.12020427.x

Xia, J., Yamaji, N., Kasai, T., and Ma, J. F. (2010). Plasma membrane-localized transporter for aluminum in rice. Proc. Natl. Acad. Sci. U.S.A. 107, 18381-18385. doi: 10.1073/pnas.1004949107

Xiao, H., Yin, L., Xu, X., Li, T., and Han, Z. (2008). The iron-regulated transporter, MbNRAMP1, isolated from Malus baccata is involved in Fe, Mn and Cd trafficking. Ann. Bot. 102, 881-889. doi: 10.1093/aob/mcn178 
Yamaji, N., Sasaki, A., Xia, J. X., Yokosho, K., and Ma, J. F. (2013). A node-based switch for preferential distribution of manganese in rice. Nat. Commun. 4:2442. doi: $10.1038 /$ ncomms3442

Yang, T. J., Perry, P. J., Ciani, S., Pandian, S., and Schmidt, W. (2008). Manganese deficiency alters the patterning and development of root hairs in Arabidopsis. J. Exp. Bot. 59, 3453-3464. doi: 10.1093/jxb/ern 195

Yanykin, D. V., Khorobrykh, A. A., Khorobrykh, S. A., and Klimov, V. V. (2010). Photoconsumption of molecular oxygen on both donor and acceptor sides of photosystem II in Mn-depleted subchloroplast membrane fragments. Biochim. Biophys. Acta 1797, 516-523. doi: 10.1016/j.bbabio.2010.01.014

Yen, M. R., Tseng, Y. H., and Saier, M. H. Jr. (2001). Maize Yellow Stripe1, an iron-phytosiderophore uptake transporter, is a member of the oligopeptide transporter (OPT) family. Microbiology 147, 2881-2883.

Yoon, S., Miller, E. W., He, Q., Do, P. H., and Chang, C. J. (2007). A bright and specific fluorescent sensor for mercury in water, cells, and tissue. Angew. Chem. Int. Ed. Engl. 46, 6658-6661. doi: 10.1002/anie.200701785

Zhang, Y., Xu, Y. H., Yi, H. Y., and Gong, J. M. (2012). Vacuolar membrane transporters OsVIT1 and OsVIT2 modulate iron translocation between flag leaves and seeds in rice. Plant J. 72, 400-410. doi: 10.1111/j.1365-313X.2012.05088.x

Zhao, H., and Eide, D. (1996a). The yeast ZRT1 gene encodes the zinc transporter protein of a high-affinity uptake system induced by zinc limitation. Proc. Natl. Acad. Sci. U.S.A. 93, 2454-2458. doi: 10.1073/pnas.93.6.2454
Zhao, H., and Eide, D. (1996b). The ZRT2 gene encodes the low affinity zinc transporter in Saccharomyces cerevisiae. J. Biol. Chem. 271, 23203-23210. doi: 10.1074/jbc.271.38.23203

Conflict of Interest Statement: The authors declare that the research was conducted in the absence of any commercial or financial relationships that could be construed as a potential conflict of interest.

Received: 20 December 2013; accepted: 05 March 2014; published online: 01 April 2014.

Citation: Socha AL and Guerinot ML (2014) Mn-euvering manganese: the role of transporter gene family members in manganese uptake and mobilization in plants. Front. Plant Sci. 5:106. doi: 10.3389/fpls.2014.00106

This article was submitted to Plant Nutrition, a section of the journal Frontiers in Plant Science.

Copyright (c) 2014 Socha and Guerinot. This is an open-access article distributed under the terms of the Creative Commons Attribution License (CC BY). The use, distribution or reproduction in other forums is permitted, provided the original author(s) or licensor are credited and that the original publication in this journal is cited, in accordance with accepted academic practice. No use, distribution or reproduction is permitted which does not comply with these terms. 